IZA DP No. 4971

What Linear Estimators Miss: Re-Examining the Effects of Family Income on Child Outcomes

Katrine V. Løken

Magne Mogstad

Matthew Wiswall

May 2010 


\title{
What Linear Estimators Miss: Re-Examining the Effects of Family Income on Child Outcomes
}

\author{
Katrine V. Løken \\ University of Bergen \\ Magne Mogstad \\ Statistics Norway \\ and IZA \\ Matthew Wiswall \\ New York University
}

\author{
Discussion Paper No. 4971 \\ May 2010 \\ IZA \\ P.O. Box 7240 \\ 53072 Bonn \\ Germany \\ Phone: +49-228-3894-0 \\ Fax: +49-228-3894-180 \\ E-mail: iza@iza.org
}

\begin{abstract}
Any opinions expressed here are those of the author(s) and not those of IZA. Research published in this series may include views on policy, but the institute itself takes no institutional policy positions.

The Institute for the Study of Labor (IZA) in Bonn is a local and virtual international research center and a place of communication between science, politics and business. IZA is an independent nonprofit organization supported by Deutsche Post Foundation. The center is associated with the University of Bonn and offers a stimulating research environment through its international network, workshops and conferences, data service, project support, research visits and doctoral program. IZA engages in (i) original and internationally competitive research in all fields of labor economics, (ii) development of policy concepts, and (iii) dissemination of research results and concepts to the interested public.
\end{abstract}

IZA Discussion Papers often represent preliminary work and are circulated to encourage discussion. Citation of such a paper should account for its provisional character. A revised version may be available directly from the author. 
IZA Discussion Paper No. 4971

May 2010

\section{ABSTRACT \\ What Linear Estimators Miss: Re-Examining the Effects of Family Income on Child Outcomes*}

This paper uses a rich Norwegian dataset to re-examine the causal relationship between family income and child outcomes. Motivated by theoretical predictions and OLS results that suggest a nonlinear relationship, we depart from previous studies in allowing the marginal effects on children's outcomes of an increase in family income to vary across the income distribution. Our nonlinear IV and fixed-effect estimates show an increasing, concave relationship between family income and children's educational attainment and IQ. The linear estimates, however, suggest small, if any, effect of family income, because they assign little weight to the large marginal effects at the lower part of the income distribution.

JEL Classification: $\quad \mathrm{J} 13, \mathrm{C} 21, \mathrm{C} 23$

Keywords: family income, child development, nonlinearities, fixed effects estimation, instrumental variables estimation, linear models

Corresponding author:

Magne Mogstad

Research Department

Statistics Norway

P.O. Box 8131 Dep.

$\mathrm{N}-0033$ Oslo

Norway

E-mail: magne.mogstad@ssb.no

\footnotetext{
* Financial support from the Norwegian Research Council (194347/S20) is gratefully acknowledged. Thanks to Rolf Aaberge, Arild Aakvik, Christian Brinch, Kjell Lommerud, Arvid Raknerud and Mark Votruba for helpful comments and suggestions.
} 


\section{Introduction}

Despite a large body of evidence showing a positive association between family income and child development, there is much controversy about whether these correlations can be given causal interpretations. Unobservable determinants of children's outcomes that are correlated with family income, like parental abilities, are of major concern when assessing the causal impact of family income on child development. While most previous studies have used family-specific fixed effects estimators to eliminate biases from permanent family characteristics, a recent strand of the literature exploits quasi-natural experiments to instrument for family income 1

Although these studies represent a significant step forward, the evidence is far from conclusive: some studies report small and sometimes insignificant effects of family income on child outcomes, whereas other suggest substantial positive effects. ${ }^{2}$ There are several possible explanations for the conflicting conclusions reached in previous studies. On the one hand, Duncan et al. (2009) advocate that these differences might be because studies rely on different data sources, gathered in different countries at different times. On the other hand, Dahl and Lochner (2008) argue that the discrepancy in the results may be because FE estimators do not control for endogenous transitory shocks (e.g. parental job loss or promotion, family illness, residential moves) and likely suffer from greater attenuation bias (because measurement error is greater for family income measured in differences than in levels).

In this paper, we take a different perspective, exploring whether the use of linear fixed effect (FE) and instrumental variables (IV) estimators, as in previous studies, can lie behind the diverging results. The reliance on linear FE and IV estimators, in which child outcome is specified as a linear function of family income, is worrisome for two reasons. The first reason is that economic theory, as well as a large body of descriptive evidence,

\footnotetext{
${ }^{1}$ See surveys by Mayer (1997), Solon (1999) and Almond and Currie (2010)

${ }^{2}$ While the IV estimates reported in Oreopoulos et al. (2005), Dahl and Lochner (2008) and Milligan and Stabile (2007) suggest some positive effects of family income on children's (short-run) outcomes, Shea (2000) and Løken (2010) find little, if any, impact of family income. Using FE estimation, both Duncan et al. (1998) and Levy and Duncan (2000) find that family income is important for children's educational attainment, whereas Blau (1999) and Dooley and Stewart (2004) find a small effect of family income on child outcome.
} 
suggests a nonlinear relationship. In particular, the seminal model of Becker and Tomes (1979, 1986) indicates an increasing concave relationship. This is because parents with low family income are more likely to be credit constrained and will therefore under-invest in their children's human capital.$^{3}$ The marginal return on human capital will therefore exceed that on assets in credit constrained families. This implies that poor parents will invest more of an increase in family income in children's human capital compared to rich parents who would give more as bequests. The theoretical prediction of a concave relationship is supported by the OLS estimates reported in Blau (1999) and Duncan et al. (2009), suggesting a much stronger association between childhood family income and child development in poor families than in rich families, both in the US and in Norway.

The second reason is that econometric theory tells us that the linear FE and IV estimators will, in general, capture marginal effects at different parts of the family income distribution ${ }^{4}$ This implies that a linear FE estimate is expected to differ from a linear IV estimate when the marginal effects are non-constant, even if there is no measurement error or omitted variables bias. To fix ideas, suppose that the causal relationship between family income and child outcomes is approximately concave. In such a case, a study using an instrument that affects family income in the upper part of the family income distribution would produce a lower linear IV estimate than a study using an instrument shifting the family income of poor families. A linear FE estimate, on the other hand, would be relatively large in a situation where income shocks largely pertain to poor families (e.g. due to parental job loss or a welfare reform), compared to the case where rich families experience most of the time variation in income (e.g. due to fluctuations in dividends and capital income).

\footnotetext{
${ }^{3}$ As emphasized by Heckman (2008), there are two distinct types of credit constraints operating on the family and its children, which can produce a nonlinear relationship between family income and child outcome. The first constraint is the inability of parents to borrow against their children's future income to finance investment in them. The second constraint is the inability of parents to borrow against their own income to finance investment in their children. See also Heckman (2008) for a discussion of evidence suggesting that credit constraints operating in childhood actually affect children's ability and educational outcome as adults.

${ }^{4}$ See Angrist and Imbens (1995) and Angrist and Krueger (1999) for a discussion of how the linear IV and OLS estimators can be decomposed into weighted averages of specific marginal effects, where the IV and OLS weights generally differ, and Mogstad and Wiswall (2010) for an assessment of how the differences in weighting matters for causal inference from linear models.
} 
A concern is therefore that the linear FE and IV estimates might present an incomplete and even misleading picture of the causal relationship between family income and child outcomes. For example, they may be far from the population average treatment effect, or some other policy-relevant treatment effect.5. Moreover, the linearity restriction may prevent us from reaching a consensus about the causal link between family income and child outcomes. To examine these issues, we start out by following the previous literature in applying linear FE and IV estimators to draw causal inference about the effect of family income on child outcomes. Then we depart from previous studies in two ways. First, to determine what linear FE and IV estimators actually identify, we estimate how they weight the marginal effects at different parts of the family income distribution. Second, to allow the marginal effects of an increase in family income to vary across the family income distribution, we relax the linearity restriction in the FE and IV estimation.

We use the same data as Løken (2010), administrative registers for the entire population of Norway, with information on children's educational attainment and IQ as adults as well as their family income during childhood. In addition, we follow Løken (2010) in exploiting regional and time variation in the economic boom that followed the initial discovery of oil in Norway, as the instrument for family income. In doing so, we are able to control for unobserved permanent differences between children born in different years as well as between children born in different areas. An advantage of our data set is that it allows us to perform both IV and FE estimation. We can therefore rule out country differences as a source of disparities. In addition, by using administrative data rather then self-reported surveys, we reduce the problem of measurement error in family income. Consequently, different levels of attenuation bias become a less likely source of discrepancy between the FE and IV estimates.

As in the previous literature, our linear OLS estimates indicate a positive and sizable effect of family income on children's IQ and educational attainment as adults. However, when estimating a non-parametric model in family income, we find a concave relationship with large marginal effects at the lower part of the family income distribution. Figure

\footnotetext{
${ }^{5}$ See Heckman and Vytlacil (2001) for a discussion of policy-relevant treatment effects.
} 
1 provides a sense of how poor the linear approximation is to the empirical relationship. This figure plots the marginal effects from a linear, quadratic and cubic model across the income distribution. The concave pattern between family income and children's education, evident in both the quadratic and cubic OLS results, raises doubts about the appropriateness of the linearity restriction in IV and FE estimation.

Our linear FE and IV results show estimates of family income on children's IQ and educational attainment that are insignificant and typically close to zero. In the spirit of previous studies, our results could be interpreted as suggesting little, if any, causal effect of family income on children's outcomes, once omitted variables bias is addressed by IV or FE techniques. However, unless the causal relationship between family income and child outcome is approximately linear, this conclusion rests on the weights attached to the marginal effects being similar across the estimators.

To compute these weights, we draw on previous work showing how the linear OLS and IV estimator can be decomposed into weighted averages of the marginal effects (Angrist and Imbens, 1995; Angrist and Krueger, 1999). To our knowledge, however, such a decomposition does not exist for the linear FE estimator. We therefore develop a decomposition of the linear FE estimator, which shows how it weights the marginal effects according to which family income levels the within-family income variation occurs. This decomposition allows us to directly compare the linear FE weighting to that of the linear OLS and IV estimators. We also provide a numerical algorithm that straightforwardly calculates the FE weights for any data set. We further demonstrate that both linear IV and FE estimators may assign negative weights to some marginal effects. The possibility of negative weights underscores that we need to be cautious about employing these linear estimators in situations where the underlying relationship is likely to be nonlinear. For example, with negative weights the linear IV and FE estimators are no longer restricted to lie between the maximum and minimum marginal effects. Further, they might produce a negative (positive), or zero estimate, even if all the marginal effects are strictly positive (negative).

When computing the weights, it is reassuring to find that both the linear IV and 
FE estimators assign non-negative weight to every marginal effect in our particular application. However, the distribution of weights is quite different across the estimators. Specifically, the linear IV estimator assigns little weight to the marginal effects at the lower part of the income distribution, illustrating that the oil boom did not do much for family income of poor families. We also find that poor families in Norway experienced little within-family income variation, implying that marginal effects in the middle and upper part of the income distribution are weighted heavily in the linear FE estimator. The fact that our IV and FE estimators assign very little weight to the marginal effects at the lower part of the income distribution could explain why they suggest small, if any, effect of family income on child outcome. In comparison, the sizable linear OLS estimate assign much more weight to marginal effects in the lower part of the income distribution.

To directly test whether the linearity restriction drive the conclusions drawn about the causal relationship between family income and child outcome, we specify child outcome as a quadratic function of family income. In doing so, we can examine how the estimated family income effects change when allowing the marginal effects to vary across the family income distribution. We then find that the IV and FE estimates suggest a concave causal relationship, with marginal effects at the lower part of the family income distribution that are several orders of magnitude larger than the marginal effects at the middle and upper part of the family income distribution. Our quadratic specification is intended to achieve a reasonable tradeoff between flexibility in functional form and achieving sufficient precision. We admittedly cannot rule out that an even more flexible specification would provide a better approximation of the causal relationship between family income and child outcome. At the very least, our quadratic model nests the linear model, and is therefore an improvement over the linear specification in family income used in the FE and IV estimation in previous studies.

This paper unfolds as follows. Section 2 discusses what linear OLS, IV and FE estimators identify. Section 3 describes our data and discusses the natural experiment used as an instrument for family income. Section 4 presents the empirical results, before Section 5 summarizes and concludes with a discussion of policy implications. 


\section{What Linear Estimators Identify}

In this section, we discuss the implications of nonlinearities for the interpretation and comparison of linear OLS, IV, and FE estimators. For simplicity, this section ignores control variables, but we will include them in the empirical analysis.

\subsection{Potential outcomes, linearity, and marginal effects}

Let $f_{i}(c)$ denote the potential (or latent) outcome that child $i$ would receive with level $c$ of childhood family income. In the context of a theoretical model of the relationship between family income and child outcome, the functional form of $f_{i}(c)$ may be determined by aspects of individual behavior and/or market forces, like in Becker and Tomes (1979, 1986). With or without an explicit theoretical model for $f_{i}(c)$, however, we can think of this function as describing the outcome level that child $i$ would achieve if he or she was assigned childhood family income $c$ (e.g. in an experiment).

The observed level of family income for child $i$ is denoted by $C_{i}$. The standard regression framework used in the literature to link the potential outcome to the observed outcome, $y_{i}$, has the following form

$$
y_{i}=f_{i}\left(C_{i}\right)=\mu+\beta C_{i}+\epsilon_{i}
$$

This model forms the basis for previous studies using OLS, IV, and FE techniques to examine the impact of family income on child outcomes. In addition to assuming constant marginal effects of additional family income, it says that the functional relationship of interest is the same for all individuals. The only individual-specific component is the mean-zero error component $\epsilon_{i}$, which captures unobserved factors determining child outcome.

Our point of departure is to relax the linearity assumption and allow the marginal effects on children's outcomes of an increase in family income to vary across the family income distribution, as theory suggests. Let family income take on values in the finite set $C_{i} \in\{0,1, \ldots, \bar{c}\}$. Using dummy variables constructed as $d_{c i}=1\left\{C_{i} \geq c\right\}$, we can specify 
a non-parametric model in family income

$$
y_{i}=\mu+\sum_{c=1}^{\bar{c}} \gamma_{c} d_{c i}+\epsilon_{i} .
$$

The $\gamma_{c}$ coefficient then represents the marginal effect of a one unit (e.g. USD 1) increase from family income level $c-1$ to $c$. There are $\bar{c}$ distinct marginal effects: $\gamma_{1}, \ldots, \gamma_{\bar{c}}$. In contrast, the standard linear model (1) assumes that the marginal effects are the same for all family income margins: $\gamma_{c}=\beta$ for all $c>06$

\section{$2.2 \quad$ OLS decomposition}

The OLS estimand for $\beta$ in (1) is $\beta(O L S)=\operatorname{Cov}\left(y_{i}, C_{i}\right) / \operatorname{Var}\left(C_{i}\right)$. Angrist and Krueger (1999), drawing on results from Yitzhaki (1996), show that the linear OLS estimand can be decomposed in the following way:

$$
\beta(O L S)=\sum_{c=1}^{\bar{c}} \gamma_{c}(O L S) w_{c}(O L S),
$$

where the OLS estimand of $\gamma_{c}$ is given by

$$
\gamma_{c}(O L S)=E\left[y_{i} \mid C_{i}=c\right]-E\left[y_{i} \mid C_{i}=c-1\right]
$$

and the associated OLS weight is defined as

$$
w_{c}(O L S)=\frac{q_{c}}{\sum_{j=1}^{\bar{c}} q_{j}},
$$

with

$$
q_{c}=\left(E\left[C_{i} \mid C_{i} \geq c\right]-E\left[C_{i} \mid C_{i}<c\right]\right)\left(\operatorname{pr}\left(d_{c i}=1\right)\left(1-\operatorname{pr}\left(d_{c i}=1\right)\right) .\right.
$$

The OLS weights are non-zero, sum to 1, and can be directly estimated using the sample

\footnotetext{
${ }^{6}$ It should be noted that both $(1)$ and 2 restrict the functional form to be the same for all children. We do so to focus attention on the issue of non-constant marginal effects. As discussed below, even if there is heterogeneity in the marginal effects, $\gamma_{c}$ is still interpretable as the average marginal effect of increasing family income from $c-1$ to $c$, such that $E\left[\gamma_{c i}\right]=\gamma_{c}$.
} 
analog of the above expressions.

There are two issues with OLS estimation. First, as emphasized in the previous literature, OLS estimates will be biased if observed family income $C_{i}$ is correlated with the unobserved components of the child outcome, $\epsilon_{i}$. Using (2), we can re-write the OLS estimand of the marginal effect as

$$
\gamma_{c}(O L S)=\gamma_{c}+\triangle_{c},
$$

where $\triangle_{c}=E\left[\epsilon_{i} \mid C_{i}=c\right]-E\left[\epsilon_{i} \mid C_{i}=c-1\right]$ represents the omitted variables bias in $\gamma_{c}(O L S)$.

The second issue, which has received less attention in previous studies, is that the linear OLS estimand has a particular weighting over the marginal effects given by (3). Specifically, weight is given to each $\gamma_{c}$ in proportion to the conditional mean of $C_{i}$, above and below $c$. More weight is also given to marginal effects close to the sample median of $C_{i}$, since this is where $\operatorname{pr}\left(d_{c i}=1\right)\left(1-\operatorname{pr}\left(d_{c i}=1\right)\right.$ is maximized. If there are nonlinearities in the OLS estimates of the marginal effects $\left(\gamma_{c}(O L S) \neq \gamma_{c^{\prime}}(O L S)\right.$ for $\left.c \neq c^{\prime}\right)$, then it follows from (3) that the linear OLS estimate depends on how it weights the marginal effects, and thereby the sample distribution of family income. Depending on the weights, the linear OLS estimate will range between the maximum and minimum $\gamma_{c}(O L S)$.

\subsection{IV decomposition}

Angrist and Imbens (1995) provide an analogous decomposition of the linear IV estimand in the case of binary instrument and under an assumption of monotonicity. As our empirical analysis uses a multi-valued instrument, we generalize their decomposition result, and moreover, discuss how the linear IV estimator may assign negative weights to some marginal effects if monotonicity does not hold.

Consider the case of a scalar (binary or multi-valued) instrument $z_{i}$. Suppose that the standard IV assumptions hold:

Assumption A1 (Instrument Uncorrelated with Residual): $\operatorname{Cov}\left(\epsilon_{i}, z_{i}\right)=0$. 
Assumption A2 (Instrument Correlated with Family Income): $\operatorname{Cov}\left(C_{i}, z_{i}\right) \neq 0$.

These assumptions imply that the instrument is uncorrelated with the unobserved factors determining child outcomes, and that the instrument has some effect on family income.

Under Assumptions A1 and A2, the IV estimand for $\beta$ in (1) is $\beta(z)=\operatorname{Cov}\left(y_{i}, z_{i}\right) / \operatorname{Cov}\left(C_{i}, z_{i}\right)$. To decompose $\beta(z)$ into a weighted average of the marginal effects $\gamma_{c}$, substitute for $y_{i}$ in (2), which yields

$$
\begin{aligned}
& \operatorname{Cov}\left(y_{i}, z_{i}\right)=\operatorname{Cov}\left(\left(\mu+\gamma_{1} d_{1 i}+\cdots+\gamma_{\bar{c}} d_{\bar{c} i}+\epsilon_{i}\right), z_{i}\right) \\
& =\gamma_{1} \operatorname{Cov}\left(d_{1 i}, z_{i}\right)+\cdots+\gamma_{\bar{c}} \operatorname{Cov}\left(d_{\bar{c}, i}, z_{i}\right)+\operatorname{Cov}\left(\epsilon_{i}, z_{i}\right) .
\end{aligned}
$$

Under Assumptions A1 and A2, we then have:

$$
\beta(z)=\sum_{c=1}^{\bar{c}} w_{c}(z) \gamma_{c}
$$

where

$$
w_{c}(z)=\frac{\operatorname{Cov}\left(d_{c i}, z_{i}\right)}{\operatorname{Cov}\left(C_{i}, z_{i}\right)}
$$

These weights sum to one, and can be computed using the sample analog of the expression above.7

From (4), we learn that $\beta(z)$ is a weighted average of the marginal effects across the family income distribution. The weight $w_{c}(z)$ attached to $\gamma_{c}$ depends on the proportion of children who, because of the instrument, experience a change in family income from less than $c$ to $c$ or more. Hence, $\beta(z)$ assigns more weight to the marginal effects for the levels of family income that are most affected by the particular instrument chosen.

One important feature of the linear IV estimand is that the weights $w_{c}(z)$ are functions of the chosen instrument $z_{i}$, implying that other instruments can lead to different weights and different $\beta(z)$. If there are nonlinearities in the marginal effects $\left(\gamma_{c}(z) \neq \gamma_{c^{\prime}}(z)\right.$

\footnotetext{
${ }^{7}$ To see that the $w_{c}(z)$ weights sum to 1 , note that $C_{i}=\sum_{c=1}^{\bar{c}} d_{c i}$, so that $\operatorname{Cov}\left(C_{i}, z_{i}\right)=$ $\sum_{c=1}^{\bar{c}} \operatorname{Cov}\left(d_{c i}, z_{i}\right)$.
} 
for $c \neq c^{\prime}$ ), linear IV estimators based on different instruments will generally produce disparate estimates of the effect of family income. Hence, previous studies may have reached conflicting conclusions about the effect of family income on child outcome, because their linear IV estimates capture marginal effects at different parts of the family income distribution. For example, the fact that Dahl and Lochner (2008) report substantial positive effects of family income, whereas Løken (2010) finds little if any effect, may simply be because of nonlinearities: While the Earned Income Tax Credit welfare reform instrument used in the former study primarily changed the family income of relatively poor families, the oil boom instrument used in the latter study had the largest impact on the middle and upper part of the family income distribution.

From (4), it is clear that some (but not all) $w_{c}(z)$ might be negative. Negative weights occur in situations where the the instrument increases family income at some family income margins, but decreases it at other margins, so that $\operatorname{Cov}\left(d_{c i}, z_{i}\right)$ varies in sign depending on $c$. This might occur, for example, if the instrument is based on some re-distributive policy change in which poor families receive additional family income, whereas rich families experience a reduction in income due to higher taxes. The possibility of negative weights has some troubling implications. First of all, $\beta(z)$ is not necessarily restricted to lie between the maximum and minimum $\gamma_{c}$, when the IV weights are negative. As a consequence, $\beta(z)$ may not be representative of any particular marginal effect or subset of marginal effects. An additional implication of negative IV weights is that the linear IV estimator can be negative (positive) even if all the marginal effects are strictly positive (negative).

To ensure non-negative weights, one may follow Angrist and Imbens (1995) in assuming monotonicity, which means that the instrument affects everyone in the same way, if at all. Under this assumption, $\operatorname{Cov}\left(d_{c i}, z_{i}\right)$ has the same sign for all $c$. With monotonicity and a binary instrument, it follows straightforwardly that (4) coincides with the IV decomposition proposed by Angrist and Imbens (1995).8

\footnotetext{
${ }^{8}$ If $z$ is binary then the IV weights in (4) can be expressed as

$$
w_{c}(z)=\frac{\operatorname{pr}\left(d_{c i}=1 \mid z_{i}=1\right)-\operatorname{pr}\left(d_{c i}=1\right)}{\sum_{s=1}^{\bar{c}} \operatorname{pr}\left(d_{s i}=1 \mid z_{i}=1\right)-\operatorname{pr}\left(d_{s i}=1\right)},
$$
}




\subsection{FE decomposition}

We next move to developing a novel decomposition of the linear FE estimator. This decomposition allows us to understand how the FE estimator weights the various marginal effects and directly compare the linear FE weighting to that of the linear OLS and IV estimators.

As the FE estimator requires information on outcomes and family income for pairs of siblings, we need to extend the cross-sectional setup used in the discussion of the OLS and IV estimators to a panel data setting. Let $C_{b j}$ denote observed childhood family income of sibling $b$ from family $j$, which as above is assumed to take on values in the finite set $C_{b j} \in\{0,1, \ldots, \bar{c}\}$. Let $f_{b j}(c)$ represent the potential outcome that child $b$ from family $j$ would receive with level $c$ in childhood family income. For simplicity, we focus our attention on the two sibling FE estimator, so that $b \in\{1,2\}$.

The motivation for FE estimation is the concern that OLS estimates could be biased because of some fixed unobserved family characteristic correlated with family income and child outcomes, e.g. inheritable parental characteristics. Suppose that siblings share a common family-specific fixed effect, $\mu_{j}$, which is potentially heterogeneous in the population and possibly correlated with the level of family income. The potential outcome for sibling $b \in\{1,2\}$ from family $j$ can then be linked to the observed outcome, $f_{b j}\left(C_{b j}\right)$, in the following way:

$$
y_{b j}=f_{b j}\left(C_{b j}\right)=\mu_{b j}+\sum_{c=1}^{\bar{c}} \gamma_{c} d_{c b j}+\epsilon_{b j},
$$

where $d_{c b j}=1\left\{C_{b j} \geq c\right\}$ and $\mu_{b j}=\mu_{j}+\alpha_{b}$, where $\mu_{j}$ is the family-specific fixed effect and $\alpha_{b}$ is a sibling-specific $b \in\{1,2\}$ intercept. Without loss of generality, we normalize $\alpha_{1}=0$, implying that $\mu_{1 j}=\mu_{j}$ and $\mu_{2 j}=\mu_{j}+\alpha_{2}$. Restricting the siblings to have the same intercept is of course a special case of (5) where $\alpha_{2}=0.9$

The linear FE model restricts the marginal effects of additional income to be constant

since $\operatorname{Cov}\left(d_{c i}, z_{i}\right)=\operatorname{pr}\left(z_{i}=1\right)\left[\operatorname{pr}\left(d_{c i}=1 \mid z_{i}=1\right)-\operatorname{pr}\left(d_{c i}=1\right)\right]$.

${ }^{9}$ In a two period panel model, the $\alpha_{2}$ term allows for a time-specific fixed effect. For example, if siblings were ordered by sequence of birth in the first difference transformation, $\alpha_{2}$ would be a birth order fixed effect. 
across the family income distribution, $\gamma_{c}=\beta$ for all $c$, and is given by

$$
y_{b j}=\mu_{b j}+\beta C_{b j}+\epsilon_{b j} .
$$

As is well known, the family-specific fixed effects can be eliminated by taking a difference transformation of (6) between all pairs of siblings, which yields the first-differences model:

$$
\Delta y_{j}=\alpha_{2}+\beta \Delta C_{j}+\Delta \epsilon_{j}
$$

where $\Delta y_{j}=y_{2 j}-y_{1 j}, \Delta C_{j}=C_{2 j}-C_{1 j}$, and $\Delta \epsilon_{j}=\epsilon_{2 j}-\epsilon_{1 j}$ are the sibling difference in outcome, family income during childhood, and the residual 10 For notational purposes, and without loss of generality, we sort siblings by their family income before taking the difference transformation, so that $\Delta C_{j} \geq 0$ for all $j$. This implies that $\Delta C_{j} \in\{0,1, \ldots, \bar{c}\}$, so that both family income levels and family income changes take on the same possible values 11

The linear FE estimand for $\beta$ in (6) is $\beta(F E)=\operatorname{Cov}\left(\Delta y_{j}, \Delta C_{j}\right) / \operatorname{Var}\left(\Delta C_{j}\right)$, and can be obtained by performing OLS on (7). In line with the previous literature, we consider the following FE assumptions:

A3 (Mean-Independence of Family Income Variation): $E\left[\Delta \epsilon_{j} \mid \Delta C_{j}\right]=0$.

A4 (Existence of Family Income Variation): $\operatorname{Var}\left(\Delta C_{j}\right) \neq 0$.

Assumption A3 implies that the differences between siblings in unobservables are uncorrelated with the differences in family income during their childhood. Assumption A4 is satisfied if there is some variation between siblings in their childhood family income. Under these assumptions, the sample analogue of $\beta(F E)$ provides a consistent estimate of $\beta$.

\footnotetext{
${ }^{10} \mathrm{An}$ alternative way to eliminate the family-specific fixed effects is to mean-difference, yielding the numerically equivalent "within" estimator.

${ }^{11}$ In our empirical analysis, we include birth order fixed effects to control for any differences in outcomes due to birth order. We have also made sure that all our FE estimates as well as the FE weights are invariant with respect to whether we sort the siblings by birth order or family income level.
} 
Following the OLS decomposition defined by (3), the linear FE estimand can straightforwardly be decomposed into:

$$
\beta(F E)=\sum_{s=1}^{\bar{c}} \psi_{s} \lambda_{s}
$$

where the marginal effect of increasing the change in family income by one unit from $s-1$ to $s$ is given by

$$
\lambda_{s}=E\left[\Delta y_{j} \mid \Delta C_{j}=s\right]-E\left[\Delta y_{j} \mid \Delta C_{j}=s-1\right]
$$

and the weight assigned to $\lambda_{s}$ is defined as

$$
\psi_{s}=\frac{\kappa_{s}}{\sum_{j=1}^{\bar{c}} \kappa_{j}}
$$

with

$$
\kappa_{s}=\left(E\left[\Delta C_{j} \mid \Delta C_{j} \geq s\right]-E\left[\Delta C_{j} \mid \Delta C_{j}<s\right]\right)\left(\operatorname{pr}\left(\Delta C_{j} \geq s\right)\left(1-\operatorname{pr}\left(\Delta C_{j} \geq s\right)\right) .\right.
$$

As with the OLS weights, the weights $\psi_{s}$ are non-zero and sum to 1 . The $\psi_{s}$ weights reflect the distribution of within-family income variation, rather than the distribution of family income levels.

A major drawback with the decomposition (8) is that it does not reveal how the linear FE estimator weights the marginal effects increases in family income levels, since $\lambda_{s}$ is a weighted average of the various marginal effects $\gamma_{1}, \ldots, \gamma_{\bar{c}}$. There is therefore no one-to-one correspondence between $\lambda_{s}$ and any particular marginal effect $\gamma_{c}$. The reason is that a given change in family income can occur at different family income levels. In Theorem 1, we therefore provide a decomposition of the linear FE estimator $\beta(F E)$ into a weighted average of the family income marginal effects $\gamma_{c}$, where the weights depend on which family income levels the within-family income variation occurs. Unlike (8), this decomposition allows us to directly compare the linear FE weighting to that of the linear OLS and IV estimators. 
A simplified example with three values of family income helps to understand the more general result presented in Theorem 1. Suppose that $C_{b j}$, and thereby $\Delta C_{j}$, takes the values 0,1 , or 2 . For every pair of siblings, there are 6 possible combinations of childhood family income, which under Assumption A3 generate the following expected differences in siblings' outcomes:

$$
\begin{array}{ll}
C_{1 j}=0, \Delta C_{j}=0: & E\left[\Delta y_{j} \mid C_{1 j}=0, \Delta C_{j}=0\right]=\alpha_{2} \\
C_{1 j}=0, \Delta C_{j}=1: & E\left[\Delta y_{j} \mid C_{1 j}=0, \Delta C_{j}=1\right]=\alpha_{2}+\gamma_{1} \\
C_{1 j}=0, \Delta C_{j}=2: & E\left[\Delta y_{j} \mid C_{1 j}=0, \Delta C_{j}=2\right]=\alpha_{2}+\gamma_{1}+\gamma_{2} \\
C_{1 j}=1, \Delta C_{j}=0: & E\left[\Delta y_{j} \mid C_{1 j}=1, \Delta C_{j}=0\right]=\alpha_{2} \\
C_{1 j}=1, \Delta C_{j}=1: & E\left[\Delta y_{j} \mid C_{1 j}=1, \Delta C_{j}=1\right]=\alpha_{2}+\gamma_{2} \\
C_{1 j}=2, \Delta C_{j}=0: & E\left[\Delta y_{j} \mid C_{1 j}=2, \Delta C_{j}=0\right]=\alpha_{2}
\end{array}
$$

From (8), it follows that

$$
\beta(F E)=\psi_{1} \lambda_{1}+\psi_{2} \lambda_{2}
$$

where $\psi_{s}$ and $\lambda_{s}$ are defined as above. Let $p_{c}(s)=\operatorname{pr}\left(C_{1 j}=c \mid \Delta C_{j}=s\right)$. By iterating expectations over family income levels $C_{1 j}$ in $\lambda_{s}$, we obtain

$$
\lambda_{1}=p_{0}(1) \gamma_{1}+p_{1}(1) \gamma_{2},
$$

and

$$
\begin{aligned}
\lambda_{2} & =\left(\gamma_{1}+\gamma_{2}\right)-\left(p_{0}(1) \gamma_{1}+p_{1}(1) \gamma_{2}\right) \\
& =\left(1-p_{0}(1)\right) \gamma_{1}+\left(1-p_{1}(1)\right) \gamma_{2},
\end{aligned}
$$

These expressions show that $\lambda_{1}$ and $\lambda_{2}$ are weighted averages of the marginal effects of interest $\gamma_{1}$ and $\gamma_{2}$. For brevity, we use the compact notation $h_{s c}$ to denote the conditional probabilities associated with a particular $\gamma_{c}$ at a given $\lambda_{s}$. In our simplified example, this implies that $h_{11}=p_{0}(1), h_{12}=p_{1}(1), h_{21}=\left(1-p_{0}(1)\right), h_{22}=\left(1-p_{1}(1)\right)$. Note that 
$\sum_{c=1}^{2} h_{s c}=1$ for $s=1,2$. By inserting these expressions for $\lambda_{1}$ and $\lambda_{2}$ in $\beta(F E)$, we get that

$$
\begin{gathered}
\beta(F E)=\psi_{1}\left\{h_{11} \gamma_{1}+h_{12} \gamma_{2}\right\}+\psi_{2}\left\{h_{21} \gamma_{1}+h_{22} \gamma_{2}\right\} \\
=w_{1}(F E) \gamma_{1}+w_{2}(F E) \gamma_{2},
\end{gathered}
$$

where

$$
w_{1}(F E)=\psi_{1} h_{11}+\psi_{2} h_{21},
$$

and

$$
w_{2}(F E)=\psi_{1} h_{12}+\psi_{2} h_{22} .
$$

Note that $w_{1}(F E)$ and $w_{2}(F E)$ sum to one, and $\beta(F E)$ is therefore a weighted average of the marginal effects $\gamma_{1}$ and $\gamma_{2}$. Each weight consists of two types of components. The component $\psi_{s}$ reflects the proportion of children with change in family income $s$. The component $p_{c}(s)$ represents the proportion of children with level $c$ of family income, given that they had a within-family income change of size $s$. Together, these components determine the weights the linear FE estimator assigns to the various marginal effects of increases in family income levels.

Theorem 1 states the general FE decomposition for any finite number of family income levels.

Theorem 1 Suppose that Assumptions A3 and A4 hold. Then,

$$
\beta(F E)=\sum_{c=1}^{\bar{c}} w_{c}(F E) \gamma_{c}
$$

where 


$$
w_{c}(F E)=\sum_{s=1}^{\bar{c}} \psi_{s} h_{s c}
$$

and $\sum_{c=1}^{\bar{c}} w_{c}(F E)=1$.

Proof See Appendix.

This decomposition is quite general and can be applied to any two-period panel data setting which satisfies Assumptions A3 and A4. The Appendix provides a numerical algorithm from which the linear $\mathrm{FE}$ weights $w_{c}(F E)$ can be estimated from the joint distribution of family income levels and family income changes. Marginal effects for family income levels that experience most of the within-family income variation receive the most weight in the linear FE estimand. If there are nonlinearities $\left(\gamma_{c} \neq \gamma_{c}\right.$ for $\left.c \neq c^{\prime}\right)$, then it follows that $\beta(F E)$ depends on how the marginal effects are weighted, and thereby the sample distribution of within-family income variation.

One implication of the dependence of $\beta(F E)$ on the sample distribution of withinfamily income variation, is that the linear FE estimate can vary from sample to sample, even if the marginal effects are the same. Consequently, caution is called for when comparing linear FE results across studies. For example, if the relationship between family income and child outcome is approximately concave, a linear FE estimate will be declining with the share of within-family income variation that is experienced by rich families.

In the above example with three values of family income, $\beta(F E)$ always assigns nonnegative weights to each marginal effect of increases in family income levels. However, as stated in Proposition 1, this does not hold true in the more general case, in which $w_{c}(F E)$ can be negative for some $\gamma_{c}$. As shown in the proof of Proposition 1, negative weights will occur in situations where the proportion of the population that experience a particular within-family income variation is sufficiently large, and moreover, where this variation is concentrated around certain family income levels.

Proposition 1 If $\bar{c}>2$, then $\beta(F E)$ may have $w_{c}(F E)<0$ for some (but not all) $c$.

Proof See Appendix. 
The possibility of negative weights on marginal effects underscores that we need to be cautious in employing a linear FE estimator in situations where the underlying relationship is likely to be nonlinear. As stated in Corollary $1, \beta(F E)$ is not necessarily restricted to lie between the maximum and minimum $\gamma_{c}$, when family income takes on more than three values. As a consequence, $\beta(F E)$ may not necessarily be representative of any particular marginal effect or subset of marginal effects.

Corollary 1 If $\bar{c}>2$, then $\beta(F E)$ may be strictly larger than the maximum $\gamma_{c}$ or strictly lower than the minimum $\gamma_{c}$.

Proof Follows directly from the proof of Proposition 1

A second implication, stated in Corollary 2, is that the linear FE estimator can be negative (positive) or zero even if all the marginal effects are strictly positive (negative), when family income takes on more than than 3 values. This means that it is possible that family income can have a strictly positive effect on children's outcome at all family income margins $\left(\gamma_{c}>0\right.$ for all $\left.c\right)$, but the linear FE estimator is negative $(\beta(F E)<0)$.

Corollary 2 If $\bar{c}>2$, then it is possible that $\beta(F E) \leq 0$ even if $\gamma_{c}>0$ for all $c=1, \ldots, \bar{c}$, or $\beta(F E) \geq 0$ even if $\gamma_{c}<0$ for all $c=1, \ldots, \bar{c}$.

Proof Follows directly from the proof of Proposition 1

\subsection{Comparison of Linear Estimators}

As is evident from the above decompositions, the linear OLS, IV and FE estimators in general assign different weights to the underlying marginal effects. Hence, we need to be cautious when comparing the results from these linear estimators, which may differ simply due to the differences in weighting.

Following Hausman (1978), a standard test of selection bias is to compare the linear OLS and IV estimates. The idea is that if family income is exogenous, the OLS and IV estimates would differ only by sampling error. From (1) and (4), we can express the differences between the linear OLS and IV estimand as 


$$
\beta(O L S)-\beta(z)=\sum_{c=1}^{\bar{c}}\left(w_{c}(O L S)-w_{c}(z)\right) \gamma_{c}+w_{c}(O L S) \triangle_{c}
$$

which illustrates that the linear OLS estimate will, in general, differ from the linear IV estimate even there is no omitted variables bias $\left(\triangle_{c}=0\right.$ for all $\left.c\right)$. For example, some of the IV weights $w_{c}(z)$ on the marginal effects can be zero if the chosen instrument $z_{i}$ does not shift family income at this margin. In comparison, the linear OLS estimand places positive weight on every marginal effect in the empirical support of the sample.

By the same token, we need to be cautious in drawing inference about the validity of a linear FE estimate by comparing it to a linear IV estimate, as they will generally differ even if there is no omitted variables bias because of different weighting. To see this, note that the difference between the linear FE and IV estimand can be expressed as

$$
\beta(F E)-\beta(z)=\sum_{c=1}^{\bar{c}}\left(w_{c}(F E)-w_{c}(z)\right) \gamma_{c} .
$$

For example, suppose that the relationship between family income and child outcome is approximately concave. In such a case, a linear IV estimator using an instrument affecting family income in the lower part of the family income distribution would produce a relatively large estimate, compared to what a linear FE estimator would produce if most of the within-family income variation occurs among high income families.

\section{Data and background}

This section describes our data and discusses the natural experiment used as an instrument for family income, before displaying descriptive statistics.

\subsection{Data and sample selection}

As in Løken (2010), our empirical analysis utilizes several registry databases provided by Statistics Norway. The data include a rich longitudinal dataset containing records for every Norwegian from 1967 to 2006 . The variables captured in this dataset include 
individual demographic information (sex, birth year, marital status, number of children, etc.), and socio-economic data (years of education, income, etc). Importantly, the dataset includes personal identifiers for one's parents, allowing us to link children to their parents and siblings, as well as family identifiers, allowing us to link spouses. Moreover, the dataset includes geographic identifiers for county of birth. The family and demographic files are merged through the personal identifiers with detailed information on children's educational attainment as adults, reported by Norwegian educational establishments, as well as data for males on their IQ test scores, collected from the Norwegian military records. In Norway, military service is compulsory for every able young man. In a robustness check, we will also exploit the fact that the military records also have information on adult height (reported in centimeters).

In the empirical analysis, we use two analytical samples. In both samples, we exclude children with missing parental identifiers. As explained below, in the IV estimation we select children born in the treatment and control counties in the years 1965, 1967, 1968 and 1969. Unlike Løken (2010), we also perform FE estimation on a sample of sibling pairs. To get sufficient precision in the FE estimates, our FE sample comprises sibling pairs born in 1965 and between 1967 and 1977, in the treatment and control counties. This serves two purposes. First, by increasing the sample size we get an adequate number of siblings. Second, by having siblings further spaced apart we obtain more within-family income variation. To provide direct comparison of the OLS vs. IV results as well as the OLS vs. FE results, we perform OLS estimation in both the IV and FE sample.

Throughout the paper, we use three different measures for children's outcomes: years of education, whether the individual is a high-school drop out, and an IQ test score. Years of education is defined as the number of completed years of education in 2006, whereas high-school drop out is defined as not obtaining a three year high school diploma by 2006 . In 2006, the children in our sample are at least 29 years old, which ensures that almost all have completed their education. Unlike these two outcome measures, the IQ test score is only available for males because they are collected from military records, and military service is compulsory for men only. Before entering the military, 
their medical and psychological suitability is assessed; this occurs for the great majority between their eighteenth and twentieth birthday. The IQ test score at these ages is particularly interesting as it is about the time of entry to the labor market or to higher education. The IQ test score is a composite score from three timed tests - arithmetic, word similarities, and figures (see Thrane, 1997, Sundet et al. 2004, 2005). The composite IQ test score is an un-weighted mean of the three sub-tests. The IQ score is reported in stanine (Standard Nine) units, a method of standardizing raw scores into a nine point standard scale that has a discrete approximation to a normal distribution, a mean of 5 , and a standard deviation of 2. We have IQ scores on about 84 percent of all Norwegian men born in the years we consider ${ }^{12}$

We follow Løken (2010) in our definition of family income. Income is taken from tax registers, and includes all market income, from wages and self-employment, as well as (taxable) cash benefits such as unemployment benefits, disability benefits, and sickness pay. We deflated the income to real 1999 income, by using the average yearly consumer price index. In every year, we add the income of the child's mother to her spouse's income (if she is married), to create one variable reflecting annual family income. This means that we measure family income as the total income of the family that the child lived in, regardless of whether the spouse of the mother is the child's biological father. We then define family income during childhood as the average annual family income from age 1 until age 11.

\subsection{Natural experiment}

We follow Løken (2010) in exploiting time and regional variation in the economic boom that followed the initial (offshore) discovery of oil in Norway as a source to exogenous variation in childhood family income ${ }^{13}$ Our motivation for using the initial discovery of

\footnotetext{
${ }^{12}$ Eide et al (2005) examine patterns of missing IQ data for the men in the 1967-1987 cohorts. Of those, 1.2 percent died within 1 year and 0.9 percent died between 1 year of age and registering with the military at about age 18. About 1 percent men had emigrated before age 18, and 1.4 percent were exempted because they were permanently disabled. An additional 6.2 percent of scores are missing for a variety of reasons, most notably foreign citizenship.

${ }^{13}$ See Løken (2010) for a detailed discussion of the oil boom, and a number of results supporting the validity of this natural experiment as a source of exogenous variation in family income.
} 
oil as a natural experiment is twofold. First, the extent to which childhood family income of children born in a given year are affected by the subsequent oil boom depends on the geographical proximity of their place of birth to the offshore oil fields. And second, for children born in the same place, the effect of the oil boom on childhood family income depended on their year of birth. In particular, our first stage of the 2SLS will be a difference-in-differences specification, exploiting that the oil boom most strongly affected the childhood family income of children born in the years right before the discovery of oil, in the county located just off the coast of the offshore oil fields.

At the end of 1969, the first major oil discovery was made in the North Sea in Norway, and in June 1970, the public was informed of it. Eventually, the discovery of oil fueled the entire Norwegian economy, but Rogaland county was the first and most strongly influenced because the main oil production in the relevant period was located off the coast there $\sqrt{14}$ The large increase in labor demand from the oil industry gradually spilled over into higher wages also for other types of jobs.

To avoid threats to the validity of the instrument from endogenous migration, the sample used in the IV estimation consists of the cohorts born just prior to the initial discovery of oil in Norway. The treatment group consists of the subsample of children born in Rogaland county, whose families were exposed to the oil boom to a greater extent than families elsewhere in Norway, because of Rogaland's geographical proximity to the offshore oil fields. As these children grew up, this led to a rise in family income in Rogaland compared to other counties of Norway. The control group comprises children born in ten other counties that are geographically distant from the offshore oil fields, but with similar family and child characteristics as those in Rogaland ${ }^{15}$ In general, there are long driving distances between the populated areas of the counties of Norway, as they are mostly far

\footnotetext{
${ }^{14}$ When oil was discovered, Norwegian authorities decided to make Stavanger, the largest city in Rogaland, the country's principle oil base. The Norwegian national oil company, Statoil, and the Norwegian Petroleum Directorate were located there in 1972. Soon, other oil companies followed. While less educated individuals were hired to do basic work in the oil production in the North Sea, people with college education, often engineers, worked in oil companies located in and around Stavanger.

${ }^{15}$ These counties are Sør-Trøndelag, Hedmark, Vestfold, Aust-Agder, Oppland, Telemark, Sogn og Fjordande, Møre og Romsdal, Nord-Trøndelag, and Buskerud. The eight excluded counties are: (i) Oslo and Akershus, comprising the capital and the surrounding urban area, (ii) Finmark, Troms, and Nordland, the three northernmost counties, and (iii) Aust-Agder and Hordaland, the close neighboring counties to Rogaland.
} 
apart or partitioned by mountains and/or the fjord-gashed shoreline.

As discussed in Løken (2010), before Norway discovered oil, Rogaland was a typical Norwegian county whose main economic activities revolved around fish and agriculture. This is mirrored in the descriptive statistics reported Table 2, showing that children in Rogaland had very similar individual and parental characteristics as those from the control counties. It also should be noted that the oil boom had little, if any, impact on local public spending on schooling in Rogaland compared to other Norwegian counties. This is in part because of the unitary school system in Norway, ${ }^{16}$ but also due to the fact that public oil revenues went directly to the central government and were re-distributed to the counties independently of proximity to the offshore oil fields. Hence, the instrument will pick up variation in family income due to higher labor demand in the affected county, rather than greater public goods expenditures in this area. When the children in our sample were old enough to start their higher education, ${ }^{17}$ the oil boom was already incorporated in the economy, so that there were no (observable) differences between Rogaland and the rest of Norway in returns to education.

Even if children from the treatment group have very similar observable characteristics as children from the control group, we cannot rule out that they have different unobserved family and child characteristics, and therefore would have different educational attainment and test scores in the absence of the discovery of oil. To address this concern, we not only include children from the treatment and control group born in the years immediately before the reform, 1967-1969, but also children born a couple of years earlier, in 1965 . Our instrument is defined as belonging to the treatment group interacted with being born in the years 1967-1969. The first stage is then a difference-in-differences estimate of the effect on family income of being born in Rogaland instead of one of the control counties for the 1967-1969 cohorts compared to the 1965 cohort. Our first and second stage specifications therefore include fixed effects for birth cohort and county of birth,

\footnotetext{
${ }^{16}$ In this unified school system, the curriculum was federally determined to ensure that the educational standards are met nationwide, and there was no room for different types of schools existing in parallel, with the result that there were virtually no private schools. Moreover, expenditure per student across municipalities were very similar.

${ }^{17}$ The first cohort in the IV sample, born in 1965, would normally start higher education after finishing high school in 1984
} 
controlling for unobserved permanent differences between children born in different years as well as between children born in different areas. Our estimates are very similar when excluding children born in 1965, like Løken (2010) does, in which case we cannot control for unobserved differences between children born in different areas.

\subsection{Descriptive statistics}

Table 1 provides descriptive statistics for the FE and IV samples. As displayed in Panel I, the IV sample consists of more than 120,000 children. The samples are balanced in terms of gender, and the number of siblings are on average 2.1. As expected, more fathers than mothers have attended college, and fathers are on average a few years older than mothers. For our outcome variables, we see that average education in the sample is 12.4 years and about 30 percent of the sample have not obtained a high school diploma. The average IQ test score of boys are 5 out of a scale from 1-9 (5 is the normed mean of this scale). Finally, we see that average childhood family income is around NOK 252000 (USD 43 $450)$.

As shown in Table 1, the FE sample consists of more than 202,000 children. We see that the IV and FE sample are quite similar in terms of observable characteristics. As we have added younger cohorts to the sample, the children in the FE sample are on average younger than those in the IV sample. We also see that they have slightly fewer siblings, which is attributable to the declining fertility trend over time. Parents are younger at the time of birth and have slightly more completed education. We also see that children in the FE sample are performing better in terms of the outcome measures, most likely a result of the increasing trend in educational attainment across cohorts.

Table 2 shows differences in the average outcomes for children from the treatment and control group who were born in 1967-1969, as well as those born in 1965. As is evident from the table, children from the treatment group (who were born in Rogaland) have somewhat lower educational attainment and IQ, as well as slightly higher drop out rates, compared to children from the control group (who were born in the other counties). We also see that these differences change very little across the cohorts. In a linear IV 
framework, this is suggestive of a small, if any, effect of family income on child outcomes when using the oil boom as the instrument. This is because the reduced form of the 2SLS (without controls for child and family characteristics) would be equal to the mean difference in the outcome of interest between the treatment and control group for the 1967-1969 cohorts, subtracted from the same mean difference for the 1965 cohort (i.e. a difference-in-differences estimator).

Table 2 also displays the mean differences in characteristics and family income for children from the treatment and control group who were born in 1967-1969, as well as those born in 1965 . We immediately see that the treatment and control groups are quite similar in terms of observable characteristics, and moreover, that these differences change little across cohorts. In contrast, average family income is substantially higher in the treatment group compared to the control group, especially for the 1967-1969 cohorts, which forms the basis for our first stage regressions.

Figure 2 illustrates the distribution of family income for the IV sample, compared to a normal density function. We see a clustering of family incomes at the mean. To make sure that the the observations with zero family income are not driving our findings, the robustness analysis reports results when excluding these families.

Turning attention to the FE sample, Figure 3 displays the average difference in family income between the younger and older sibling across the family income distribution. The figure illustrates that there is little within-family income variation occurring in poor families. This picture is mirrored in Table 3, reporting the mean, median, 10th and 90th percentile in the distribution of income differences between the younger and older siblings, across the family income distribution. We see that the mean income difference for the total sample is positive and around NOK 27600 (USD 4 760). When we partition the sample into family income groups by NOK 75000 (USD 12 900), we see that the median income difference increases steadily as we move upwards in the income distribution. It is also evident that there is considerable variation in income differences within each income group. 


\section{Empirical results}

This section outlines our empirical models used in the OLS, IV and FE estimation, before discussing our empirical results.

\subsection{Empirical models}

The main empirical model used in the literature is specified as

Model 1: $y_{i}=\mu_{0}+\beta C_{i}+X_{i}^{\prime} \delta+\epsilon_{i}$,

where $y_{i}$ is some outcome, $C_{i}$ is family income when the child was young, and $X_{i}$ is a set of controls. Throughout our paper, $X_{i}$ includes fixed effects for birth cohort and county of birth, as well as dummy variables for child's birth order, number of siblings, gender, parent's age and college attendance. All the control variables are measured in the year the child is born, and therefore before our variable of interest $C_{i}$.

Motivated by theoretical predictions and OLS results suggesting an increasing concave relationship between family income and child outcome, our point of departure is to allow the marginal effects of additional income to vary across the family income distribution. Specifically, we specify each child outcome to be a quadratic function of family income, yielding

Model 2: $y_{i}=\mu_{0}+\beta_{1} C_{i}+\beta_{2} C_{i}^{2}+X_{i}^{\prime} \delta+\epsilon_{i}$.

This quadratic specification is intended to achieve a reasonable tradeoff between a flexible functional form in family income and precision in the IV and FE estimation. We have, however, performed OLS estimation with higher order polynomials in family income. As illustrated in Figure 1, adding a cubic family income term barely moves the marginal effect estimates over the majority of the family income distribution. In the robustness analysis, we also perform OLS, FE and IV estimation with child outcomes specified as a linear function of $\log$ family income, because a few previous studies have used such a specification. 
To perform 2SLS estimation of Models 1 and 2, we use the following first stage specifications, where $Z_{i}$ is a set of instruments and $X_{i}$ is the same set of controls as above:

First stage, Model 1:

$$
C_{i}=Z_{i}^{\prime} \lambda+X_{i}^{\prime} \rho+\eta_{i}
$$

First stages, Model 2:

$$
\begin{gathered}
C_{i}=Z_{i}^{\prime} \lambda+X_{i}^{\prime} \rho+\eta_{i} \quad(\text { First Stage I) } \\
C_{i}^{2}=Z_{i}^{\prime} \theta+X_{i}^{\prime} \xi+v_{i} \quad \text { (First Stage II) }
\end{gathered}
$$

When performing IV estimation of Model 1, we first use a single binary instrument, equal to 1 if the child is born in Rogaland in the years 1967-1969, and 0 otherwise. We refer to this instrument as the "Rogaland dummy variable." However, to identify the parameters of both the linear and the squared family income terms in Model 2, we need more than one instrument. To construct multiple instruments, we use two different strategies. Both strategies exploit the fact that if the Rogaland dummy variable is a valid instrument, then under an assumption that $\epsilon_{i}$ is mean-independent of the included covariates $X_{i}$ (a necessary assumption for consistent IV estimation of Model 1), any function of the Rogaland dummy variable and the $X_{i}$ are valid instruments.

The first IV strategy interacts the Rogaland dummy variable with some of the control variables, and uses this set of instruments in the first stage specifications (First Stage I and II) of Model 2. Our reason for not interacting the Rogaland dummy variable with all the included control variables is that such a procedure would introduce a large number of over-identifying restrictions, which could increase the small sample bias of the IV estimator (see e.g. Staiger and Stock, 1997). As a tradeoff between small sample bias and efficiency in the IV estimation, our main specification interacts the Rogaland dummy variable with five control variables: indicator for father attended college, indicator for mother attended college, father's age, mother's age, and an indicator for large family size 
(3 or more siblings). The reason for choosing these control variables is that they generate the strongest first stage results. Importantly, to provide a direct comparison between the IV results of Models 1 and 2, we will report 2SLS results from both models using the same set of interaction instruments. As a robustness check, we also report IV results using only a subset of these interactions, as well as the IV results from interacting the Rogaland dummy variable with every included covariate.

The second IV strategy uses predicted family income and predicted family income squared as the instruments. This strategy follows closely the IV literature where the predicted treatment is used as the instrument in a conventional 2SLS procedure ${ }^{18}$ The predicted family income instruments are constructed by regressing family income on the controls, the Rogaland dummy variable, and the five interactions discussed above. From these regression coefficients, we predict family income for each child. Finally, we apply the standard 2SLS procedure using predicted family income and predicted family income squared as instruments, controlling for the $X_{i}$ variables. To provide a direct comparison between the IV results of Models 1 and 2, we also report 2SLS results from both models using the same set of predicted family income instruments.

\subsection{Linear OLS, IV and FE results}

Columns 1-3 of Table 4 report the linear OLS, IV and FE estimates for our three outcome measures: years of education, high school drop out, and IQ. The strong first stage results are reported in Table 8. From Panel I of Table 4, we see that our precise OLS result indicate a positive and sizable effect of family income on children's educational attainment and IQ as adults. To get a perspective on the magnitude of the parameter estimates, a standard deviation increase in family income (NOK 101,000 or USD 17,414) is estimated to produce slightly less than 0.5 additional years of education, a fall in high school drop out rates in the range of 5 to 6 percent, and a rise in the IQ test score of more than 0.125 of a standard deviation. Comparing the results in Panel I and III, we see that the linear

\footnotetext{
${ }^{18}$ Wooldridge (2000), Carneiro et al. (2003) and Mogstad and Wiswall (2009) provide examples of analysis using the predicted treatment as the instrument. In these applications, they find a substantial improvement in the precision of the IV estimates using the predicted treatment instruments over the IV estimates using the instruments directly.
} 
OLS estimates are similar in the IV and FE sample 19

In Panels II and IV of Table 4, we report linear IV and FE results. The FE estimates of family income on children's IQ and educational attainment are close to zero, and significantly different from the linear OLS estimates. In the spirit of previous studies, these results would be interpreted as suggesting little, if any, causal effect of family income on children's outcomes, as well as significant omitted variables bias in the OLS estimates. The IV estimates also show no sign of significant effects of family income on child outcome, although they are too imprecisely estimated to rule out some effect.

\subsection{OLS, IV and FE weights}

As discussed in Section 2, the interpretation and comparison of the linear estimates reported in Table 4 rests on the relationship between family income and child outcomes being linear or that the weights attached to the marginal effects are similar across the linear estimators. To directly examine the weighting implicit in the linear estimators, Table 5 and Figure 4 use the decomposition results in (3), (4), and (9) to compute the weight functions over the marginal effects for the linear OLS, IV, and FE estimates. In order to compute the weights, we have discretized the income distribution using family income margins of NOK 25000 (USD 4310).

From Table 5 and Figure 4, we see that the linear IV estimate assigns relatively little weight to the marginal effects at the lower part of the family income distribution, illustrating the the oil boom did not do that much for the family income of poor families. It is also evident that well-off families in Norway experience most within-family income variation, implying that marginal effects in the middle and upper part of the family income distribution contribute the most to the linear FE estimate. In comparison, the linear OLS estimator weights the different margins more evenly than the linear IV and FE estimates. In particular, the OLS estimator assigns several times more weight to marginal effects in the lower part of the family income distribution than the linear IV and FE estimator.

\footnotetext{
${ }^{19}$ When considering the IQ results, Table 4 displays a larger reduction in sample size in the FE estimation compared to the IV estimation. This is because we only have information on the IQ of men, implying that the FE estimates are identified from within-family income variation among brothers.
} 
This evidence of substantially different weighting of the marginal effects of family income underscores that we need to be cautious when interpreting and comparing the results from these linear estimators. Moreover, it serves to illustrate how different studies may have reached conflicting conclusions about the effect of family size on child outcome, because their linear estimates capture marginal effects at different parts of the family income distribution.

\subsection{Quadratic OLS, IV and FE results}

Table 7 reports OLS, IV and FE results from Model 2 in which we have relaxed the linearity restriction in Model 1 by including a squared term in family income. The strong first stage results are reported in Table 8. Panel II of Table 7 reports IV results using the interacted instruments, and Panel III shows the IV results applying the predicted family income instruments. Our main finding is that all of the results suggest a concave relationship between family income and children's outcomes, with large marginal effects at the lower parts of the family income distribution. This holds true for both the OLS and FE results, as well as in the IV estimates, regardless of the choice of instruments. Furthermore, we see a fairly precisely estimated concave pattern for all the outcomes.

To get a perspective on the magnitude of the estimated parameters, the FE estimates suggest that a standard deviation increase in income (NOK 101 000, USD 17 414) produces .22 additional years of education for a child from a family with income of NOK 150 000, whereas a child from a family with income of NOK 300000 only achieves an extra .02 years of education. In comparison, the linear IV estimates using the predicted family income instruments indicates that such an increase in family income would generate .74 additional years of education for a child from the poor family, whereas the child from the richer family would gain as little as .05 years of education.

As is evident from Table 7, the estimated family income effects differ, in some cases significantly, depending on the identification strategy used, even though they all suggest a concave relationship. In particular, our IV estimates exceed the FE (and OLS) estimates, as in Dahl and Lochner (2008). Several explanations may account for these differences. 
One is that our income collected from administrative registers is also noisily measured, so that the FE estimates suffer from more attenuation bias than the IV estimates. It is also possible that the effect of family income is greater for the complier group to our instruments, than for other children. Nor can we rule out that endogenous income shocks are biasing the FE estimates. A final possible explanation is that transitory shocks to family income creating within-family income variation may, at least partly, be smoothed out by inter-temporal income transfers, lowering the estimated effect of family income in the FE estimation.

From Table 7, we also see that the IV estimates differ somewhat, though not significantly, depending on whether we use the interacted instruments or the predicted family income instruments. This is most likely because different instruments will in general identify different local average treatment effects (see Angrist and Imbens, 1994). Table 9 therefore reports IV results from Model 1, using the same instruments as used in the IV estimates of Model 2, reported the in Table 7. Comparing the results from the linear and quadratic specification using the same set of instruments, it is clear the role of the linearity restriction in masking the family income effects. The linear IV estimates are never significantly different, and always insignificantly different from zero, whereas the quadratic IV estimates using the same set of instruments show large and significant effects of family income. Hence, we can conclude for a given set of instruments, the second stage restriction plays an important role in the conclusion of the effects of family income on child outcome. Comparing the linear and quadratic specification using the same set of instruments, we also see that relaxing the linearity restriction may yield a substantial improvement in the precision, illustrating that using linear estimators may not even be preferable on grounds of efficiency.

\subsection{Robustness analysis}

This subsection discusses a number of robustness checks, supporting the validity of our main results.

Functional form. Our quadratic specification is intended to achieve a reasonable trade- 
off between flexibility in functional form and achieving sufficient precision. We have, however, also performed the FE and IV estimation with a cubic term in family income. The coefficients associated with the cubic term are insignificant, indicating that the concave specification might be reasonable. However, we admittedly cannot rule out that an even more flexible specification would provide a better approximation of the causal relationship between family income and child outcome. At the very least, our quadratic model nests the linear model, and is therefore an improvement over the linear specification in family income used in previous studies.

We have also performed OLS estimation with higher order polynomials in family income. As illustrated in Figure 1, adding a cubic family income term has little impact on the marginal effect estimates across the majority of the family income distribution. In addition, we have performed OLS estimation discretizing the family income variable into 27 dummy variables capturing the "marginal effects" of increasing family income by NOK 25 000. As shown in Table 6, the estimates from this non-parametric approximation of family income suggests a concave relationship between family income and child outcomes that line up well with the quadratic (and cubic) OLS results, although they are quite imprecise at the uppermost part of the family income distribution where there are few observations. This indicates that the concave specification in family income, as suggested by Becker and Tomes $(1979,1986)$, might not be too crude of an approximation of the causal relationship between family income and child outcomeS.

Small sample bias. In general, the consistency and asymptotic distribution of the IV estimator is unaffected by whether we use the Rogaland dummy variable as the only instrument, or construct several instruments by interacting the Rogaland dummy variable with some control variables (see e.g. the discussion in Newey, 1990, 1993). The same holds true for whether we use the set of interacted instruments directly or the predicted family income instruments in the first stage regressions. In particular, the asymptotic variance of the IV estimator is unaffected by the initial estimation of the predicted family income instruments. However, the small sample properties of the IV estimator may be affected by whether we use the Rogaland dummy variable as the only instrument, or use multiple 
instruments by interacting the Rogaland dummy variable with some control variables. Given our large samples and strong first stage results reported in Table 8, small sample bias in the IV estimator because of multiple instruments should be of little concern (see e.g. Staiger and Stock, 1997). It is nevertheless re-assuring to find in Table 10 that the quadratic IV results when using only two interaction instruments yields very similar results as those reported in Table 7. Moreover, we see that the quadratic IV estimates change little when interacting the Rogaland dummy variable with each included control variable.

Omitted variables bias. If we could find a variable that is strongly correlated with our outcomes of interest, but unlikely to be affected significantly by family income, then we may use it to perform a placebo test to informally assess the omitted variables bias in our estimates. In this paper, we exploit variation in adult height to perform placebo tests. Height should be a promising candidate in developed countries for two reasons. First, a large number of twin and adoptive studies have shown that genetic factors are the overwhelming determinant of variation in height within developed countries, in which childhood diet is likely to be of minor importance for adult height. For example, Silventoinen et al. (2003) report heritability estimates around 0.9 for Norwegian males born between 1967 and 1978, implying that within this population about $90 \%$ of the variance in adult height can be accounted for by the variance of genes.

Second, it has long been recognized that taller adults have, on average, higher education and earnings. This also holds true in our sample where the correlation between height and our outcomes of interest are always highly significant: For example, a one standard deviation increase in height $(6.5 \mathrm{~cm})$ is associated with an increase in education by .26 years and IQ scores by .25, while lowering dropout rates by 3 percentage points. Case and Paxson (2008) offer an explanation: On average, taller people complete more education and perform better on IQ tests. As early as age 3, and throughout childhood, they find that taller children perform significantly better on cognitive tests. Moreover, they demonstrate that the correlation between height in childhood and adulthood is very high, so that tall children are much more likely to become tall adults. 
A significant effect of family income on children's adult height would raise concerns that effects on other outcomes reflect omitted variables bias, like unobserved heterogeneity in innate ability, rather than true policy impacts. Table 11 reveals that our OLS estimates show quite small but significant positive effects of family income on adult height, whereas the IV and FE estimates suggest no effect of family income on adult height. This holds true both for the linear and quadratic specification of family income. Since the placebo tests are performed only for males due to data availability, it should be noted that the IQ results are also based on the subsample of males.20

Log specification. Above, we have followed Dahl and Lochner (2008) and others in measuring family income in levels rather than logs. However, some previous studies have preferred to specify family income as a linear function of log income, perhaps to allow for the effect of income to be stronger in poor families. For comparison and as a robustness of our results, Table 12 shows results when replacing family income in levels with logs (row c) in Model 1 (excluding families with zero family income). It is reassuring to find, like in Dahl and Lochner (2008), that measuring family in logs rather than levels does not change our main results. Specifically, the linear OLS estimates indicate a positive and sizable effect of family income on children's outcome. For example, a $10 \%$ increase in family income corresponds to an additional .1 years of education. Moreover, the linear FE estimates of family income close to zero, and are significantly different from the linear OLS estimates. We also see that the linear IV estimates show no sign of significant effects of family income on child outcome, although they are too imprecisely estimated to rule out some effect. We conclude therefore that neither the linear specification in log family income nor the linear specification in level family income is able to uncover the positive, concave relationship between family income and child outcomes.

Zero income families. As a final robustness check, we make sure that our results are not driven by the small number of observations with zero family income. From the linear estimates in Table 12 we see that results excluding families with zero family income (row

\footnotetext{
${ }^{20}$ Table 11 displays a larger reduction in sample size in the FE estimation compared to the IV estimation. This is because we only have information on the height of men, implying that the FE estimates are identified from within-family income variation among brothers.
} 
b) give very similar results to the baseline estimates (row a), reported in Table 4. We do the same comparison for the quadratic estimates in Table 13. Also in this case, we find that the results without observations with zero income (row b) are very similar to the baseline estimates (row a), reported in Table $7{ }^{21}$

\section{Conclusion}

In this paper, we use a rich Norwegian data set to re-examine the causal relationship between childhood family income and child outcomes. Motivated by theoretical predictions and OLS results suggesting a nonlinear relationship, we depart from previous studies in allowing the marginal effects on children's outcomes of an increase in family income to vary across the family income distribution. The insights from our empirical analysis may be summarized in the following two conclusions.

First, linear FE and IV estimators, as used in previous studies, provide a misleading picture of the causal relationship between family size and child outcome. Specifically, our linear FE and IV results show estimates of family income on children's IQ and educational attainment that are insignificant and typically close to zero, whereas the linear OLS estimates suggest significant and sizable effects of family income. In the spirit of previous studies, our results could be interpreted as suggesting little, if any, causal effect of family income on children's outcomes, once omitted variables bias is addressed by IV or FE techniques. However, when relaxing the linearity restriction in family income, the IV and FE estimates line up with the OLS results in suggesting a concave relationship, with marginal effects at the lower part of the family income distribution that are several orders of magnitude larger than the marginal effects at the middle and upper part of the family income distribution.

Second, from the weight functions of the marginal effects behind the linear FE and IV estimators, we learn that our linear estimates suggest little, if any, impact of family income because they mostly capture the small marginal effects in the middle and upper part of

\footnotetext{
${ }^{21}$ The same holds true when dropping observations with family income above 500000 NOK, and when excluding families with family income below 40000 NOK.
} 
the family income distribution. In comparison, the linear OLS estimator assign much more weight to the lower parts of the family income distribution, with higher marginal effects. This evidence of quite different weighting of the marginal effects of family income underscores that we need to be cautious when interpreting and comparing the results from these linear estimators. Moreover, it serves to illustrate how different studies may have reached conflicting conclusions about the effect of family income on child outcomeS because their linear estimates capture the marginal effects at different parts of the family income distribution.

A general lesson to be drawn from our study is that the linearity restriction in IV and FE estimation may drive the conclusions reached in applications where there are reasons to suspect a nonlinear relationship, as in research on the return to education, the effect of family size on child outcome, and the impact of maternal smoking on child birthweight. This finding stands in stark contrast to the view advocated by Angrist and Pischke (2010), who claim that "The linear models that constitute the workhorse of contemporary empirical practice usually turn out to be remarkably robust" (p. 10). Our study echo the argument of Leamer (1983) that functional form concerns are inescapable in empirical research. In fact, IV and FE estimation may exacerbate the sensitivity of the results to functional form assumptions, because of the way they weight the underlying marginal effects. The ideal remedy is sensitivity analysis, showing how the results vary with changes in functional form. And further, one should compute the weights functions, to know what the linear estimates actually identify and interpret the results in view of that.

Our results may also be of interest from a policy perspective. Most developed countries have a range of policies targeted at family income during childhood, such as family allowances, maternity benefits, single parent benefits, and family tax credits. In fact, families with children receive special treatment under the tax-benefit system in twentyeight of the thirty OECD-countries (OECD, 2002) While some of these policies are means-tested, others are more universal of nature. Our IV and FE results suggest a con-

\footnotetext{
${ }^{22}$ See Del Boca, Flinn, and Wiswall (2010) for an analysis of the differential effects of these types of policies within an estimated household model of child development.
} 
cave relationship between family income and child outcomeS with relatively large positive effect at the lower part of the family income distribution, indicates that policies targeting poor families may be quite effective in promoting child development. 


\section{References}

Almond, D., And J. Currie (2010): "Human Capital Development Before Age Five," NBER Working Papers 15827.

Angrist, J., And J. Pischke (2010): "The Credibility Revolution in Empirical Economics: How Better Research Design Is Taking the Con out of Econometrics," Journal of Economic Perspectives, 24, 3-30.

Angrist, J. D., And G. W. Imbens (1995): "Two-Stage Least Squares Estimation of Average Causal Effects in Models with Variable Treatment Intensity," Journal of the American Statistical Association, 90, 431-442.

Angrist, J. D., And A. B. Krueger (1999): "Empirical Strategies in Labor Economics," in Handbook of Labor Economics, ed. by O. Ashenfelter, and D. Card.

Becker, G. S., And N. Tomes (1979): "An Equilibrium Theory of the Distribution of Income and Intergenerational Mobility," Journal of Political Economy, 87, 1153-89.

(1986): "Human Capital and the Rise and Fall of Families.," Journal of Labor Economics, 4, 1-39.

Blau, D. M. (1999): "The Effect of Income on Child Development," The Review of Economics and Statistics, 81, 261-276.

Carneiro, P., J. Heckman, and E. Vytlacil (2003): "Understanding What Instrumental Variables Estimate: Estimating Marginal and Average Returns to Education," Working paper.

Case, A., and C. Paxson (2008): "Stature and Status: Height, Ability, and Labor Market Outcomes," Journal of Political Economy, 116, 499-532.

Dahl, G., And L. Lochner (2008): "The Impact of Family Income on Child Achievement: Evidence from the Earned Income Tax Credit," NBER Working Papers 14599.

Del Boca, D., C. Flinn, and M. Wiswall (2010): "Household Choices and Child Development," Working paper.

Dooley, M., And J. Stewart (2004): "Family Income and Child Outcomes in Canada," Canadian Journal of Economics, 37, 898-917.

Duncan, G., K. Telle, K. Ziol-Guest, and A. Kalil (2009): "Economic Depreviation in Early Childhood and Adult Outcomes: Comparative Evidence from Norwegian Register Data and the US PSID," memo, in preparation as a chapter for a new volume on russel sage foundation edited by r.erikson, m.jannti and t.smeding.

Duncan, G., W. J. Yeung, J. Brooks-Gunn, and J. R. Smith (1998): "How Much Does Childhood Poverty Affect the Life Chances of Children?," American Sociological Review, 63, 406-423.

Eide, M., N. Øyen, R. SkJærven, S. Nilsen, T. Bjerkedal, and G. Tell (2005): "Size at Birth and Gestational Age as Predictors of Adult Height and Weight," Epidemiology, 16, 175-181. 
Hausman, J. (1978): "Specification Tests in Econometrics," Econometrica, 46, 12511271.

Heckman, J. (2008): "Econometric Causality," International Statistical Review, 76, 127.

Heckman, J., and E. Vytlacil (2001): "Policy-relevant treatment effects," American Economic Review, 91, 107-111.

Imbens, G., And J. Angrist (1994): "Identification and Estimation of Local Average Treatment Effects," Econometrica, 62, 467-475.

Leamer, E. (1983): "Let's Take the Con out of Econometrics," American Economic Review, 73, 31-43.

Levy, D. M., and G. Duncan (2000): "Using Sibling Samples to Assess the Effect of Childhood Family Income on Completed Schooling," JCPR Working Papers 168, Northwestern University.

Løken, K. V. (2010): "Family Income and Children's Education: Using the Norwegian Oil Boom as a Natural Experiment," Labour Economics, 17, 118-129.

Mayer, S. (1997): What Money Can't Buy: Family Income and Children's Life Chances. Harvard University Press.

Milligan, K., and M. Stabile (2007): "The Integration of Child Tax Credits and Welfare: Evidence from the Canadian National Child Benefit Program," Journal of Public Economics, 91, 305-326.

Mogstad, M., and M. Wiswall (2009): "How Linear Models Can Mask Non-Linear Causal Relationships. An Application to Family Size and Children's Education," Discussion Papers 586, Research Department of Statistics Norway.

NEWEy, W. (1990): "Semiparametric Efficiency Bounds," Journal of Applied Econometrics, 5, 99-135.

(1993): "Efficient Estimation of Models with Conditional Moment Restrictions," Handbook of Statistics, 11, 419-454.

OECD (2002): "Taxing Wages: 2001 edition," Discussion paper.

Oreopoulos, P., M. Page, and A. Stevens (2008): "The Intergenerational Effects of Worker Displacement," Journal of Labor Economics, 26, 455-483.

SheA, J. (2000): "Does Parents' Money Matter?," Journal of Public Economics, 77, $155-184$.

Silventoinen, K., S. Sammalisto, M. Perola, D. Boomsma, B. Cornes, C. Davis, L. Dunkel, M. De Lange, J. Harris, J. Huelmborg, et Al. (2003): "Heritability of Adult Body Height: A Comparative Study of Twin Cohorts in Eight Countries," Twin Research and Human Genetics, 6, 399-408.

Solon, G. (1999): "Intergenerational Mobility in the Labor Market," Handbook of Labor Economics, 3, 1761-1800. 
Staiger, D., And J. Stock (1997): "Instrumental Variables Regression with Weak Instruments," Econometrica, 65, 557-586.

Sundet, J., D. Barlaug, and T. Toruussen (2004): "The End of the Flynn Effect?: A Study of Secular Trends in Mean Intelligence Test Scores of Norwegian Conscripts During Half a Century," Intelligence, 32, 349-362.

Sundet, J., K. Tambs, J. Harris, P. Magnus, and T. Toruussen (2005): "Resolving the Genetic and Environmental Sources of the Correlation Between Height and Intelligence: A Study of Nearly 2600 Norwegian Male Twin Pairs," Twin Research and Human Genetics, 8, 307-311.

Thrane, V. (1977): "Evneprøving av Utskrivningspliktige i Norge 1950-1953," Arbeidsrapport nr.26, institutt for sosialforskning.

Wooldrige, J. (2002): Econometric Analysis of Cross Section and Panel Data 2rd Edition: Books. The MIT Press Cambridge, Massachusetts London, England.

YitzhAKI, S. (1996): "On Using Linear Regressions in Welfare Economics," Journal of Business and Economic Statistics, 14, 478-486. 


\section{Figures}

Figure 1: OLS estimates of marginal effects on years of education

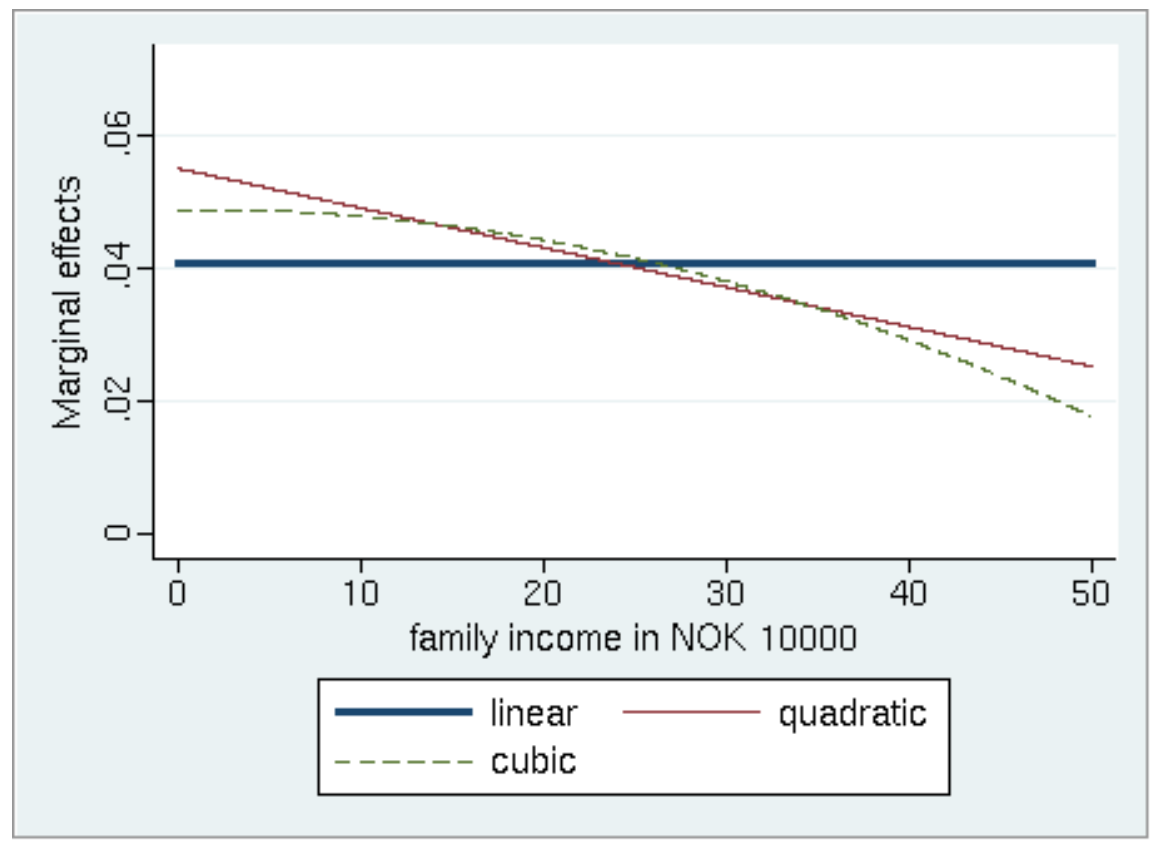

Notes: This figure uses the IV sample to graph OLS estimates of marginal effects from a linear specification in family income (Model 1), a quadratic specification in family income (Model 2), and cubic specification in family income (adding a cubic term in family income to Model 2). 
Figure 2: Density of the family income distribution

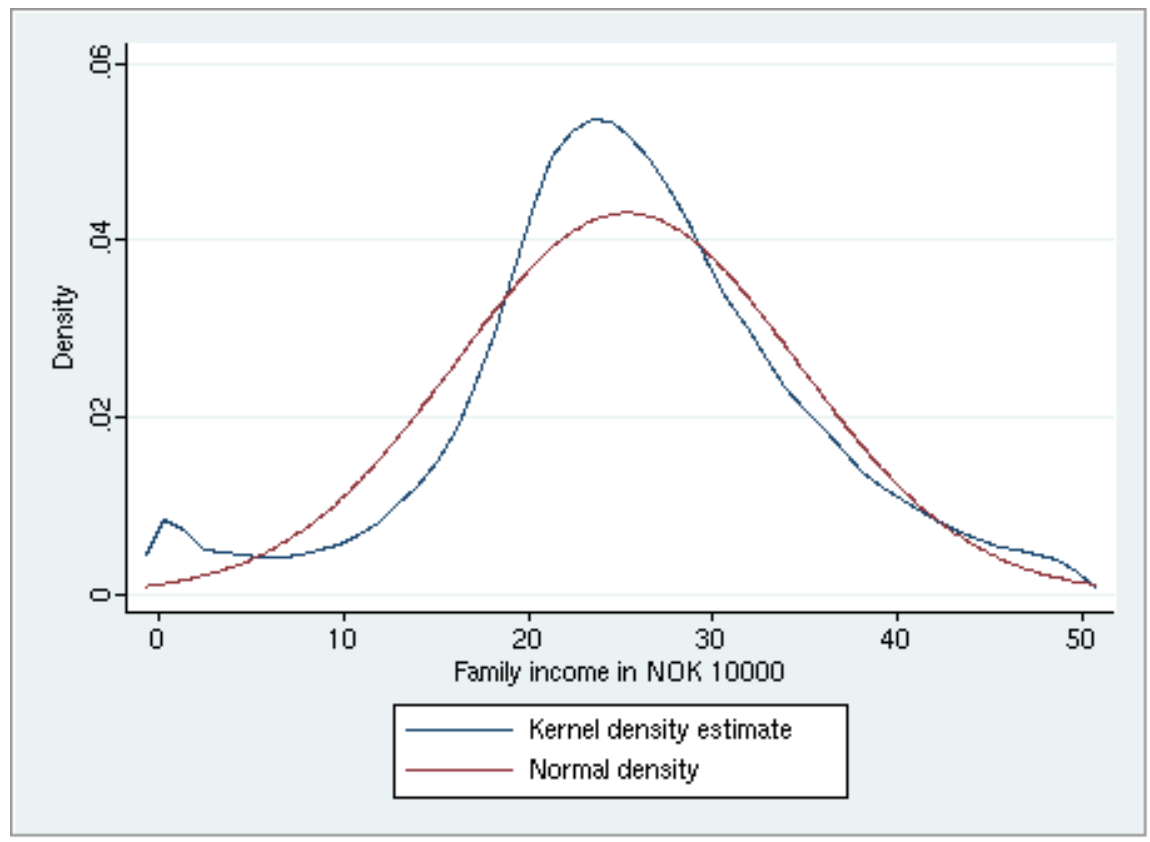

Note: This figure uses the IV sample.

Figure 3: Difference in family income between younger and older sibling across the family income distribution

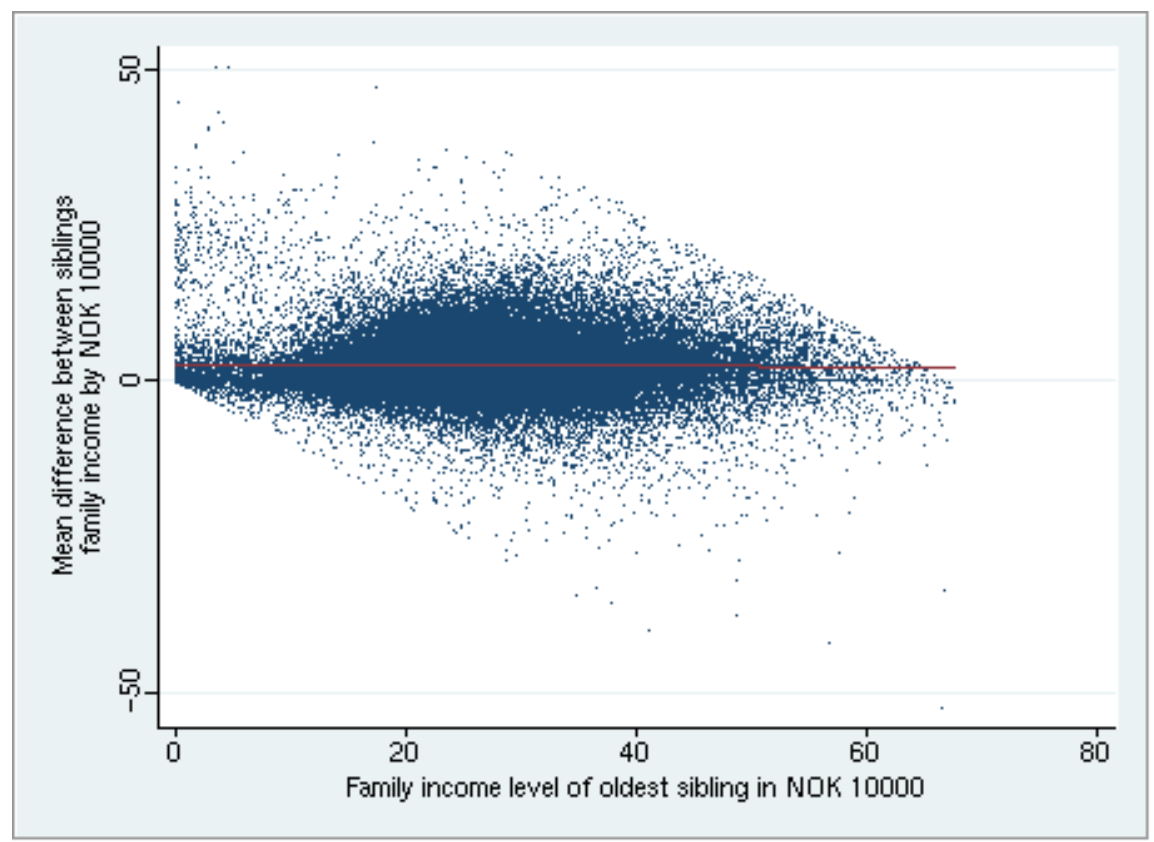

Note: This figure uses the FE sample. 
Figure 4: Linear OLS, IV and FE weights

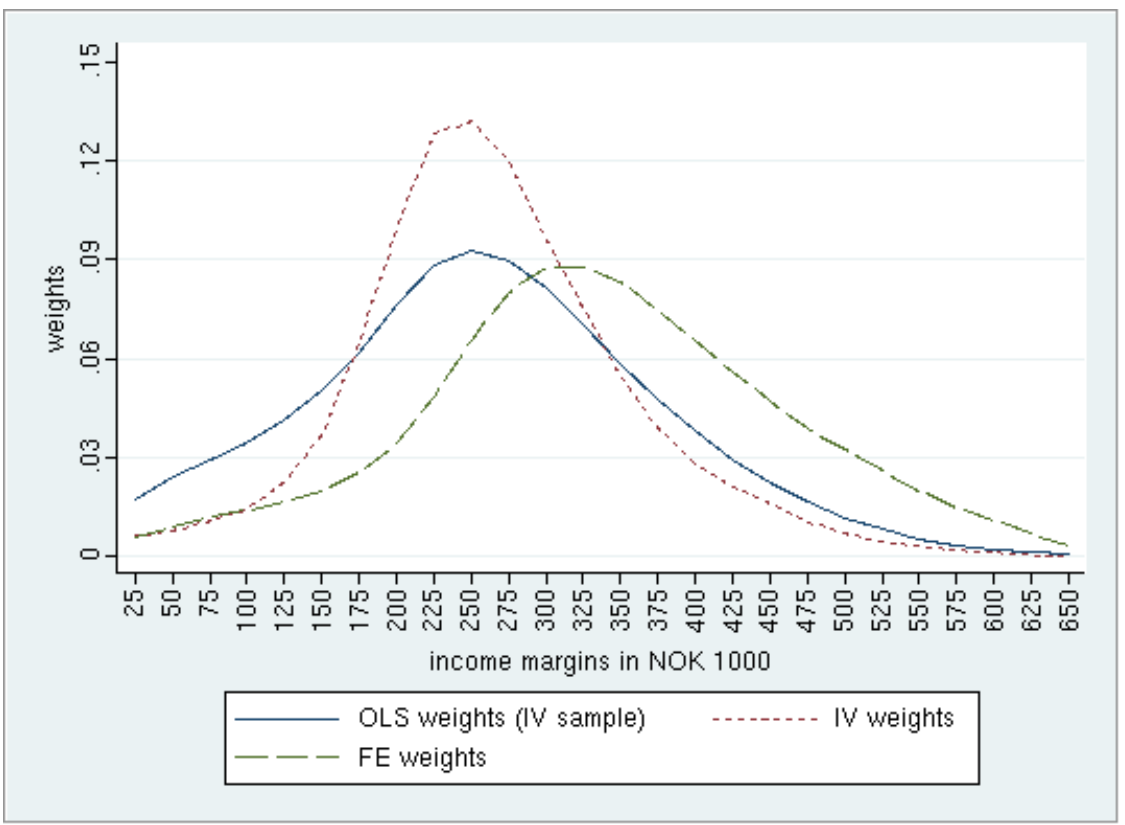

Notes: This table reports the weights for the linear OLS and IV estimates (using the IV sample), shown in Panels I and II, and the linear FE estimate (using the FE sample), shown in Panel IV of Table 4 . To compute these weights, we use the decomposition in (3), (4), (9), and income margins of NOK 25000. 


\section{Tables}

Table 1: Descriptive Statistics for IV and FE sample

\begin{tabular}{lcccc}
\hline & \multicolumn{2}{c}{ IV sample } & \multicolumn{2}{c}{ FE sample } \\
& Mean & Std. Dev. & Mean & Std. Dev. \\
\hline \hline & .49 & .50 & .49 & .50 \\
Female & 2.13 & 1.29 & 1.98 & 1.11 \\
Number of siblings & 2.20 & 1.28 & 1.91 & 1.00 \\
Birth order & .07 & .26 & .09 & .28 \\
Mother college & .16 & .37 & .17 & .38 \\
Father college & 26.7 & 5.98 & 25.2 & 4.77 \\
Mother's age when child is born & 29.9 & 7.90 & 28.3 & 5.81 \\
Father's age when child is born & 12.39 & 2.50 & 12.60 & 2.50 \\
\hline Education in 2006 & .30 & .46 & .26 & .44 \\
Dropout rate from high school & 5.01 & 1.82 & 5.11 & 1.80 \\
IQ (boys only) & \multicolumn{3}{c}{} \\
\hline Family income (child aged 2-12) & 25.2 & 10.1 & 27.5 & 10.1 \\
in 10000 NOK & 179.7 & 6.5 & 179.8 & 6.6 \\
\hline Height (males only) & 121122 & & \\
\hline $\mathrm{N}$ &
\end{tabular}

Notes: The IV sample consists of children born in 1965 and 1967-1979 in the following counties: Rogaland, Sør-Trøndelag, Hedmark, Vestfold, Aust-Agder, Oppland, Telemark, Sogn og Fjordande, Møre og Romsdal, Nord-Trøndelag, and Buskerud. The FE sample consists of children born in 1965 and 1967-1977 from the same counties. 
Table 2: Mean differences between children from the treatment and control group, by birth cohort

\begin{tabular}{lccc}
\hline & $\begin{array}{c}\text {-Levels- } \\
\text { Treatment } \\
1967-1969\end{array}$ & $\begin{array}{c}\text {-Difference (SE)- } \\
\text { Treatment-Control }\end{array}$ & $\begin{array}{c}\text {-Difference (SE)- } \\
\text { Treatment-control }\end{array}$ \\
\hline \hline Female & .49 & $-.001(.005)$ & $-.003(.008)$ \\
Number of siblings & 2.08 & $.23(.011)$ & $.19(.021)$ \\
Birth order & 2.18 & $.11(.011)$ & $.05(.021)$ \\
Mother college & .07 & $-.008(.002)$ & $-.013(.004)$ \\
Father college & .16 & $-.006(.003)$ & $.003(.006)$ \\
Mother's age & & & $.09(.101)$ \\
when child is born & 26.5 & $.22(.053)$ & \\
Father's age & & & $-.36(.138)$ \\
when child is born & 29.5 & $-.14(.069)$ & $-.209(.040)$ \\
\hline Education in 2006 & 12.27 & $-.201(.023)$ & $.012(.008)$ \\
Dropout rate from high school & .29 & $.004(.004)$ & $.049(.043)$ \\
IQ (males only) & 5.06 & $.017(.024)$ & \\
\hline Family income & & & $1.87(.157)$ \\
(child aged 2-12) & & $2.65(.090)$ & $-.51(.144)$ \\
in 10000 NOK & 26.3 & $-.58(.083)$ & 29958 \\
\hline Height (males only) & 179.3 & 91164 & \\
\hline N & 14759 & & \\
\hline
\end{tabular}

Notes: The treatment group consists of children born in Rogaland. The control group consists of children born in in Sør-Trøndelag, Hedmark, Vestfold, Aust-Agder, Oppland, Telemark, Sogn og Fjordande, Møre og Romsdal, Nord-Trøndelag, and Buskerud. 
Table 3: Distribution of Sibling Difference in Family Income

\begin{tabular}{lcccc}
\hline & mean & median & 10th & 90 th \\
\hline \hline Total sample & 2.76 & 2.16 & -1.40 & 7.85 \\
& & & & \\
\hline $\begin{array}{l}\text { Family income } \\
\text { first sibling }\end{array}$ & & & & \\
$0-75000$ & 1.70 & 0.30 & -1.70 & 5.46 \\
$75000-150000$ & 1.16 & 0.71 & -2.93 & 5.56 \\
$150000-225000$ & 1.81 & 1.35 & -1.49 & 5.81 \\
$225000-300000$ & 2.57 & 2.19 & -1.06 & 6.71 \\
$300000-375000$ & 3.33 & 3.07 & -1.34 & 8.49 \\
$375000-450000$ & 4.12 & 3.63 & -1.42 & 10.63 \\
$450000-525000$ & 4.81 & 4.12 & -1.37 & 12.65 \\
$525000-600000$ & 5.61 & 4.68 & -1.61 & 14.58 \\
$600000-675000$ & 8.10 & 6.54 & -1.07 & 21.10 \\
\hline
\end{tabular}

Notes: This table partitions the IV sample into family income (for first sibling) groups by NOK 75000 . For each group, we compute the mean, median, 10th and 90th percentile in the distribution of income differences between the younger and older siblings. 
Table 4: Linear OLS, IV and FE estimates

\begin{tabular}{lccc}
\hline & Education & Dropout & $\begin{array}{c}\text { IQ } \\
\text { (males only) }\end{array}$ \\
\hline \hline Panel I: Linear OLS & & & \\
Family income in 10000 NOK & $\begin{array}{c}.043^{* * *} \\
(.001)\end{array}$ & $\begin{array}{c}-.006^{* * *} \\
(.000)\end{array}$ & $\begin{array}{c}.028^{* * *} \\
(.001)\end{array}$ \\
\hline Panel II: Linear IV & & & \\
Instrument: & & & \\
Born in Rogaland in 67-69 & & & \\
Family income in 10000 NOK & .022 & -.012 & -.061 \\
& $(.057)$ & $(.011)$ & $(.072)$ \\
\hline N & 121122 & 121122 & 57788 \\
\hline \hline Panel III: Linear OLS & & & \\
Family income in 10000 NOK & $.041^{* * *}$ & $-.005^{* * *}$ & $.024^{* * *}$ \\
& $(.001)$ & $(.000)$ & $(.001)$ \\
\hline Panel IV: Linear FE & & & \\
$67-77$ sibling pairs & & & \\
Family income in 10000 NOK & .000 & -.001 & -.001 \\
& $(.003)$ & $(.001)$ & $(.004)$ \\
\hline N & 202424 & 202424 & 55866
\end{tabular}

Notes: This table reports OLS, IV and FE estimates of Model 1. Panels I and II use the IV sample, whereas Panel III and IV use the FE sample. Panel II uses the born in Rogaland in 1967-1969 dummy variable as the only instrument. A full set of controls is used in all regressions. Standard errors in parentheses are heteroskedastic robust. ${ }^{* * *}$ Significant at $1 \%$ level, ${ }^{* *}$ significant at $5 \%$ level, ${ }^{*}$ significant at $10 \%$ level. 
Table 5: Linear OLS, IV and FE weights

\begin{tabular}{lccc}
\hline & OLS weight & IV weight & FE weights \\
\hline \hline Income margins & & & \\
1: income $\geq 25000$ & .017 & .006 & .006 \\
2: income $\geq 50000$ & .024 & .008 & .009 \\
3: income $\geq 75000$ & .029 & .011 & .012 \\
4: income $\geq 100000$ & .035 & .014 & .014 \\
5: income $\geq 125000$ & .041 & .023 & .016 \\
6: income $\geq 150000$ & .050 & .037 & .020 \\
7: income $\geq 175000$ & .062 & .065 & .026 \\
8: income $\geq 200000$ & .076 & .099 & .034 \\
9: income $\geq 225000$ & .088 & .129 & .049 \\
10: income $\geq 250000$ & .093 & .132 & .066 \\
11: income $\geq 275000$ & .090 & .120 & .080 \\
12: income $\geq 300000$ & .081 & .097 & .088 \\
13: income $\geq 325000$ & .070 & .075 & .088 \\
14: income $\geq 350000$ & .059 & .055 & .083 \\
15: income $\geq 375000$ & .048 & .039 & .075 \\
16: income $\geq 400000$ & .038 & .028 & .065 \\
17: income $\geq 425000$ & .029 & .021 & .056 \\
18: income $\geq 450000$ & .022 & .016 & .047 \\
19: income $\geq 475000$ & .017 & .010 & .039 \\
20: income $\geq 500000$ & .012 & .007 & .032 \\
21: income $\geq 525000$ & .008 & .004 & .026 \\
22: income $\geq 550000$ & .005 & .003 & .020 \\
23: income $\geq 575000$ & .003 & .001 & .015 \\
24: income $\geq 600000$ & .002 & .001 & .011 \\
25: income $\geq 625000$ & .001 & .000 & .007 \\
26: income $\geq 650000$ & .001 & .000 & .003 \\
\hline
\end{tabular}

Notes: This table reports the weights for the linear OLS and IV estimates (using the IV sample), shown in Panels I and II, and the linear FE estimate (using the FE sample), shown in Panel IV of Table 4. To compute these weights, we use the decomposition in (3), (4), (9), and income margins of NOK 25000 
Table 6: OLS estimates of marginal effects

\begin{tabular}{lccc}
\hline \hline & Education & Dropout & IQ (males only) \\
\hline \hline Income margins & & & \\
1: $0 \leq$ income $<25000$ & .058 & -.010 & .031 \\
2: $25000 \leq$ income $<50000$ & .057 & -.009 & .031 \\
3: $50000 \leq$ income $<75000$ & .055 & -.009 & .031 \\
4: $75000 \leq$ income $<100000$ & .054 & -.008 & .030 \\
5: $100000 \leq$ income $<125000$ & .050 & -.008 & .030 \\
6: $125000 \leq$ income $<150000$ & .049 & -.008 & .030 \\
7: $150000 \leq$ income $<175000$ & .047 & -.007 & .029 \\
8: $175000 \leq$ income $<200000$ & .046 & -.007 & .029 \\
9: $200000 \leq$ income $<225000$ & .044 & -.007 & .028 \\
10: $225000 \leq$ income $<250000$ & .042 & -.006 & .028 \\
11: $250000 \leq$ income $<275000$ & .041 & -.006 & .028 \\
12: $275000 \leq$ income $<300000$ & .039 & -.005 & .027 \\
13: $300000 \leq$ income $<325000$ & .038 & -.005 & .027 \\
14: $325000 \leq$ income $<350000$ & .036 & -.005 & .027 \\
15: $350000 \leq$ income $<375000$ & .035 & -.004 & .026 \\
16: $375000 \leq$ income $<400000$ & .033 & -.004 & .026 \\
17: $400000 \leq$ income $<425000$ & .031 & -.004 & .025 \\
18: $425000 \leq$ income $<450000$ & .030 & -.003 & .025 \\
19: $450000 \leq$ income $<475000$ & .028 & -.003 & .025 \\
20: $475000 \leq$ income $<500000$ & .027 & -.002 & .024 \\
21: $500000 \leq$ income $<525000$ & .025 & -.002 & .024 \\
22: $525000 \leq$ income $<550000$ & .024 & -.002 & .023 \\
23: $550000 \leq$ income $<575000$ & .022 & -.001 & .023 \\
24: $575000 \leq$ income $<600000$ & .020 & -.001 & .023 \\
25: $600000 \leq$ income $<625000$ & .019 & -.001 & .022 \\
26: $625000 \leq$ income $<650000$ & .018 & -.000 & .022 \\
\hline
\end{tabular}

Notes: This table reports OLS estimates of marginal effects from Model 2, using predicted income and income squared and the average value of income in each income group. This will then capture the "marginal effects" of increasing family income by NOK 25 000. A full set of controls is used in each of the regressions. 
Table 7: Quadratic OLS, IV and FE estimates

\begin{tabular}{|c|c|c|c|}
\hline & \multicolumn{3}{|c|}{ Dependent variables } \\
\hline & Education & Dropout & $\begin{array}{c}\text { IQ } \\
\text { (males only) }\end{array}$ \\
\hline \multicolumn{4}{|l|}{ Panel I: Quadratic OLS } \\
\hline Family income in 10000 NOK & $\begin{array}{c}.051^{* * * *} \\
(.002)\end{array}$ & $\begin{array}{c}-.010^{* * *} \\
(.000)\end{array}$ & $\begin{array}{c}.032^{* * * *} \\
(.002)\end{array}$ \\
\hline Quadratic income (x 100) & $\begin{array}{c}-.016 * * * \\
(.005)\end{array}$ & $\begin{array}{c}.008 * * * \\
(.001)\end{array}$ & $\begin{array}{c}-.008^{*} \\
(.004)\end{array}$ \\
\hline \multicolumn{4}{|l|}{ Panel II: Quadratic IV } \\
\hline Family income in 10000 NOK & $\begin{array}{l}.180^{* *} \\
(.087)\end{array}$ & $\begin{array}{l}-.030^{*} \\
(.016)\end{array}$ & $\begin{array}{l}.234^{* *} \\
(.109)\end{array}$ \\
\hline Quadratic income (x 100) & $\begin{array}{l}-.302^{*} \\
(.164)\end{array}$ & $\begin{array}{l}.042^{*} \\
(.021)\end{array}$ & $\begin{array}{c}-.401^{* *} \\
(.210)\end{array}$ \\
\hline \multicolumn{2}{|l|}{ Instruments: Predicted income } & & \\
\hline Family income in 10000 NOK & $\begin{array}{l}.142^{* *} \\
(.072)\end{array}$ & $\begin{array}{c}-.057^{* * * *} \\
(.013)\end{array}$ & $\begin{array}{c}.195^{* * *} \\
(.070)\end{array}$ \\
\hline Quadratic income (x 100) & $\begin{array}{c}-.228^{* *} \\
(.107)\end{array}$ & $\begin{array}{c}.097^{* * *} \\
(.019)\end{array}$ & $\begin{array}{c}-.323^{* * *} \\
(.106) \\
\end{array}$ \\
\hline $\mathrm{N}$ & 121122 & 121122 & 57788 \\
\hline \multicolumn{4}{|l|}{ Panel IV: Quadratic OLS } \\
\hline Family income in 10000 NOK & $\begin{array}{c}.069^{* * *} \\
(.002)\end{array}$ & $\begin{array}{c}-.012^{* * *} \\
(.000)\end{array}$ & $\begin{array}{c}.033^{* * *} \\
(.003)\end{array}$ \\
\hline Quadratic income (x 100) & $\begin{array}{c}-.050 * * * \\
(.003)\end{array}$ & $\begin{array}{c}.013^{* * *} \\
(.001)\end{array}$ & $\begin{array}{c}-.017^{* * *} \\
(.004)\end{array}$ \\
\hline \multicolumn{4}{|l|}{ Panel V: Quadratic FE } \\
\hline Family income in 10000 NOK & $\begin{array}{c}.041^{* * *} \\
(.008)\end{array}$ & $\begin{array}{c}-.006^{* * *} \\
(.002)\end{array}$ & $\begin{array}{l}.019^{*} \\
(.010)\end{array}$ \\
\hline Quadratic income (x 100) & $\begin{array}{c}-.065 * * * \\
(.013)\end{array}$ & $\begin{array}{c}.008^{* * *} \\
(.002)\end{array}$ & $\begin{array}{c}-.031^{* *} \\
(.014)\end{array}$ \\
\hline $\mathrm{N}$ & 202424 & 202424 & 55866 \\
\hline
\end{tabular}

Notes: This table reports OLS, IV and FE estimates of Model 2. Panels I, II and III use the IV sample, whereas Panels IV and V use the FE sample. Panel II uses the set of interacted instruments (born in Rogaland in 1967-1969 dummy variable and interacting the born in Rogaland in 1967-1969 dummy variable with father's college, mother's college, father's age, mother's age and large family) in First Stages I and II, whereas Panel III uses the predicted family income instruments based on the same set of interacted instruments in First Stages I and II. A full set of controls is used in all regressions. Note that the quadratic income regressor is linear income (in 10,000 NOK) multiplied by 100, hence quadratic income is in 1,000,000 NOK. Standard errors in parentheses are heteroscedastic robust. ${ }^{* * *}$ Significant at $1 \%$ level, ${ }^{* *}$ significant at $5 \%$ level, ${ }^{*}$ significant at $10 \%$ level. 


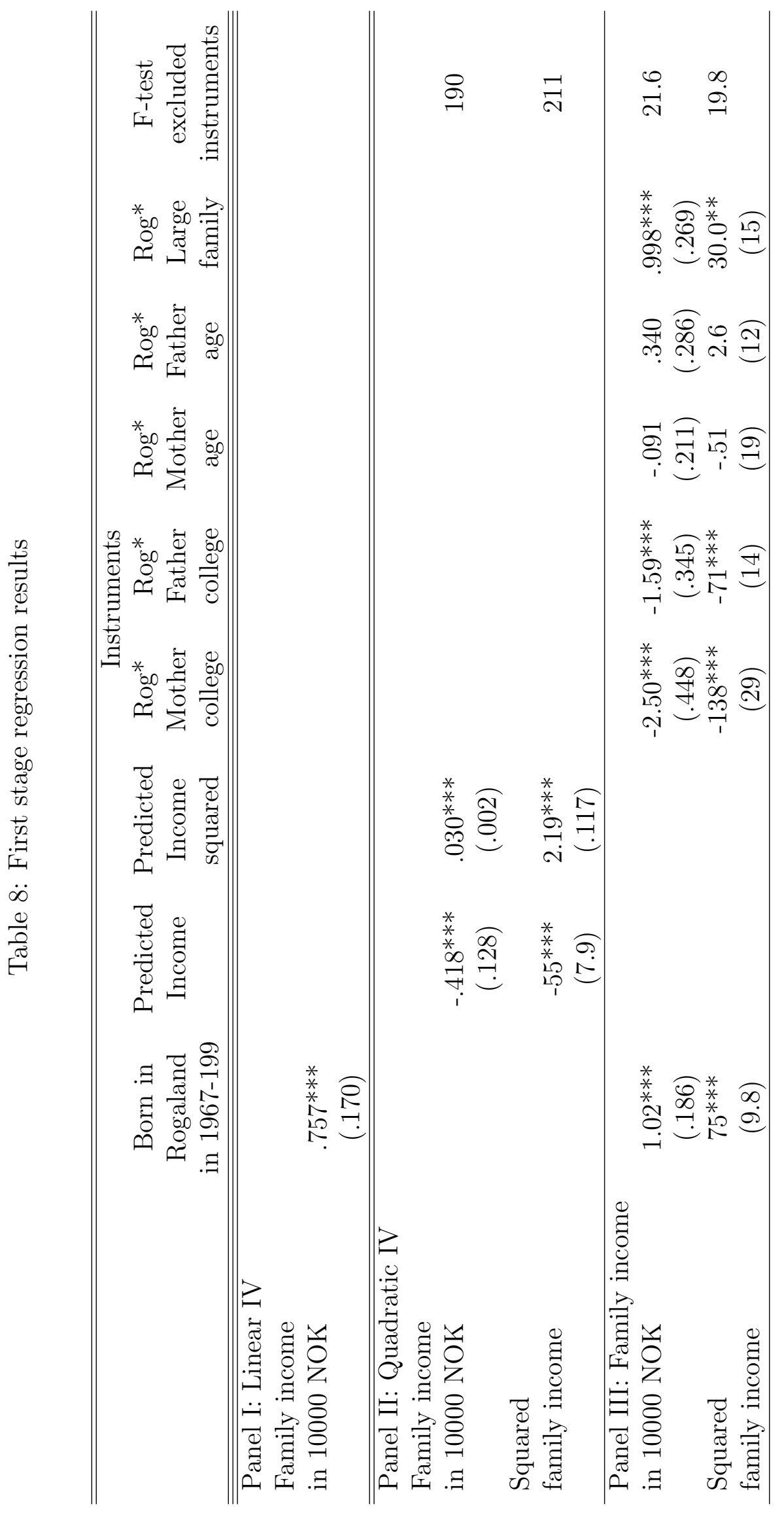

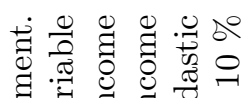

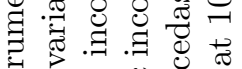

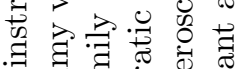

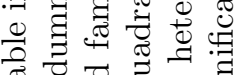

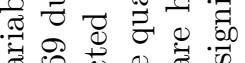
ơ

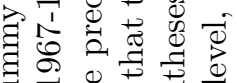
政

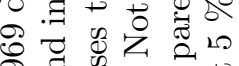

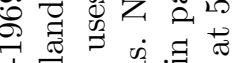

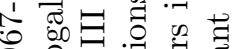
क्ष च

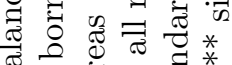

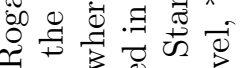
$\exists$ a :

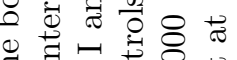
v की $\exists \vec{B}, \exists$

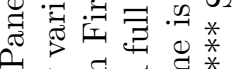

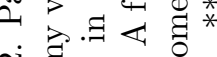

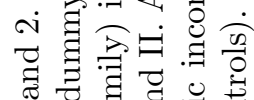
㱐 券

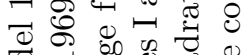

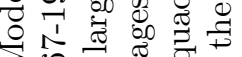

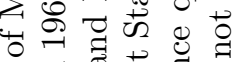

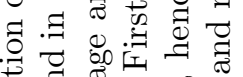
要 कु

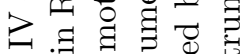

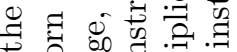
过 0.7 .

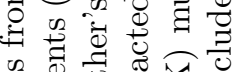

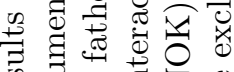

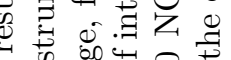

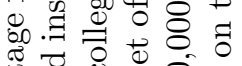
要要 800

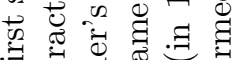

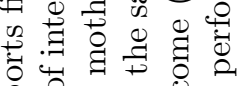
家宊

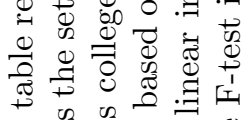

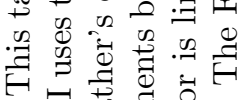

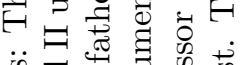

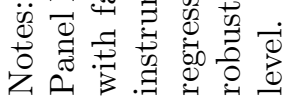


Table 9: Linear IV estimates with different instruments

\begin{tabular}{|c|c|c|c|}
\hline & \multicolumn{3}{|c|}{ Dependent variables } \\
\hline & Education & Dropout & $\begin{array}{c}\mathrm{IQ} \\
\text { (males only) }\end{array}$ \\
\hline $\begin{array}{l}\text { Panel I: Linear IV } \\
\text { Instrument: Born in Rogaland } \\
\text { in 1967-1969 }\end{array}$ & & & \\
\hline Family income in 10000 NOK & $\begin{array}{l}.022 \\
(.057)\end{array}$ & $\begin{array}{l}-.012 \\
(.011)\end{array}$ & $\begin{array}{c}.033 \\
(.023)\end{array}$ \\
\hline $\begin{array}{l}\text { Panel II: Linear IV } \\
\text { Instruments: Interactions }\end{array}$ & & & \\
\hline Family income in 10000 NOK & $\begin{array}{l}.026 \\
(.020)\end{array}$ & $\begin{array}{l}-.008 \\
(.006)\end{array}$ & $\begin{array}{l}-.017 \\
(.013)\end{array}$ \\
\hline $\begin{array}{l}\text { Panel III: Linear IV } \\
\text { Instruments: Predicted income }\end{array}$ & & & \\
\hline Family income in 10000 NOK & $\begin{array}{l}-.010 \\
(.012)\end{array}$ & $\begin{array}{l}.001 \\
(.001)\end{array}$ & $\begin{array}{l}-.018 \\
(.013)\end{array}$ \\
\hline $\bar{N}$ & 12121122 & 12121122 & 57788 \\
\hline
\end{tabular}

Notes: This table reports IV estimates of Model 1 using the IV sample. Panel I uses the born in Rogaland in 1967-1969 dummy variable instrument. Panel II uses the set of interacted instruments (born in Rogaland in 1967-1969 dummy variable and interacting the born in Rogaland in 1967-1969 dummy variable with father's college, mother's college, father's age, mother's age and large family), whereas Panel III uses the predicted family income instruments based on the same set of interacted instruments. A full set of controls is used in all regressions. Standard errors in parentheses are heteroskedastic robust. *** Significant at $1 \%$ level, ${ }^{* *}$ significant at $5 \%$ level, ${ }^{*}$ significant at $10 \%$ level. 
Table 10: Quadratic IV with different interaction instruments

\begin{tabular}{|c|c|c|c|}
\hline & \multicolumn{3}{|c|}{ Dependent variables } \\
\hline & Education & Dropout & $\begin{array}{c}\text { IQ } \\
\text { (males only) }\end{array}$ \\
\hline \multicolumn{4}{|l|}{ Panel I: Quadratic IV } \\
\hline \multicolumn{4}{|l|}{ Instruments: All interactions } \\
\hline \multirow[t]{2}{*}{ Family income in 10000 NOK } & $.178^{* *}$ & $-.046^{* * *}$ & $.171^{* *}$ \\
\hline & $(.075)$ & $(.014)$ & $(.079)$ \\
\hline \multirow[t]{2}{*}{ Quadratic income (x 100) } & $-.260^{*}$ & $.067 * *$ & $-.246^{*}$ \\
\hline & $(.139)$ & $(.022)$ & $(.149)$ \\
\hline \multicolumn{4}{|l|}{ Panel II: Quadratic IV } \\
\hline \multicolumn{4}{|l|}{ Instruments: Predicted income } \\
\hline \multirow[t]{2}{*}{ Family income in 10000 NOK } & $.199^{* * *}$ & $-.070 * * *$ & $.241^{* * *}$ \\
\hline & $(.071)$ & $(.013)$ & $(.070)$ \\
\hline \multirow[t]{2}{*}{ Quadratic income (x 100) } & $-.301 * * *$ & $.113^{* * *}$ & $-.382^{* * *}$ \\
\hline & $(.106)$ & $(.019)$ & $(.107)$ \\
\hline \multicolumn{4}{|l|}{ Panel III: Quadratic IV } \\
\hline \multicolumn{4}{|l|}{ Instruments: Interactions } \\
\hline \multirow[t]{2}{*}{ Family income in 10000 NOK } & $.207 * *$ & $-.036^{*}$ & $.256^{* *}$ \\
\hline & $(.100)$ & $(.019)$ & $(.114)$ \\
\hline \multirow[t]{2}{*}{ Quadratic income (x 100) } & $-.316^{*}$ & .045 & $-.432^{*}$ \\
\hline & $(.180)$ & $(.035)$ & $(.222)$ \\
\hline \multicolumn{4}{|l|}{ Panel IV: Quadratic IV } \\
\hline \multicolumn{4}{|l|}{ Instruments: Predicted income } \\
\hline \multirow[t]{2}{*}{ Family income in 10000 NOK } & $.192^{* *}$ & $-.072^{* * *}$ & $.212^{* * *}$ \\
\hline & $(.088)$ & $(.015)$ & $(.071)$ \\
\hline \multirow[t]{2}{*}{ Quadratic income (x 100) } & $-.288 * *$ & $.114^{* * *}$ & $-.342^{* * *}$ \\
\hline & $(.124)$ & $(.022)$ & $(.105)$ \\
\hline $\mathrm{N}$ & 121122 & 121122 & 57788 \\
\hline
\end{tabular}

Notes: This table reports IV estimates of Model 2. Panel I uses a full set of interacted instruments in First stages I and II (born in Rogaland in 1967-1969 dummy variable and interacting the born in Rogaland in 1967-1969 dummy variable with all included covariates). Panel II uses the predicted family income instruments based on this full set of interacted instruments in First Stages I and II. Panel III uses a subset of interacted instruments (born in Rogaland in 1967-1969 dummy variable and interacting the born in Rogaland in 1967-1969 dummy variable with only mothers college and large family) in First Stages I and II. Panel IV uses this the predicted family income instruments based on this subset of interacted instruments in First Stages I and II. A full set of controls is used in all regressions. Note that the quadratic income regressor is linear income (in 10,000 NOK) multiplied by 100, hence quadratic income is in 1,000,000 NOK. Standard errors in parentheses are heteroscedastic robust. ${ }^{* * *}$ Significant at $1 \%$ level, ${ }^{* *}$ significant at $5 \%$ level, ${ }^{*}$ significant at $10 \%$ level. 
Table 11: Height (males only) - robustness tests I

\begin{tabular}{lcc}
\hline & $\begin{array}{c}\text { Linear } \\
\text { Family income } \\
\text { in 10000 NOK }\end{array}$ & $\begin{array}{c}\text { Quadratic } \\
\text { Family income } \\
(\mathrm{x} \mathrm{100)}\end{array}$ \\
\hline \hline Panel I: OLS & $.034^{* * *}(.003)$ & \\
& $.047^{* * *}(.009)$ & $-.027^{*}(.016)$ \\
\hline Panel II: IV & & \\
Instrument: Born in Rogaland in $67-69$ & $-.125(.213)$ & \\
Instruments: Interactions & $.061(.409)$ & $-.163(.797)$ \\
Instruments: Predicted income & $.056(.241)$ & $-.155(.340)$ \\
\hline $\mathrm{N}$ & 61329 & 61329 \\
\hline \hline Panel III: OLS & $.033^{* * *}(.003)$ & \\
& $.058^{* * *}(.009)$ & $-.046^{* * *}(.015)$ \\
\hline Panel IV: FE & $-.007(.013)$ & \\
& $.009(.035)$ & $-.025(.049)$ \\
\hline $\mathrm{N}$ & 61322 & 61322
\end{tabular}

Notes: This table reports OLS, IV and FE estimates of Model 1 and 2. Panels I and II uses the IV sample, whereas Panel III and IV uses the FE sample. Panel II uses first born in Rogaland in 1967-1969 dummy variable as the only instrument, before using the set of interacted instruments (born in Rogaland in 1967-1969 dummy variable and interacting the born in Rogaland in 1967-1969 dummy variable with father's college, mother's college, father's age, mother's age and large family) in First Stages I and II, and finally the predicted family income instruments based on the same set of interacted instruments in First Stages I and II. A full set of controls is used in all regressions. Note that the quadratic income regressor is linear income (in 10,000 NOK) multiplied by 100, hence quadratic income is in 1,000,000 NOK. Standard errors in parentheses are heteroskedastic robust. *** Significant at $1 \%$ level, ** significant at $5 \%$ level, * significant at $10 \%$ level. 
Table 12: Linear OLS, IV and FE estimates - robustness tests II

\begin{tabular}{lccc}
\hline & Education & Dropout & $\begin{array}{c}\text { IQ } \\
\text { (males only) }\end{array}$ \\
\hline \hline Panel I: Linear OLS & & & \\
a) baseline & $.043^{* * *}(.001)$ & $-.006^{* * *}(.001)$ & $.028^{* * *}(.001)$ \\
b) drop 0 income & $.043^{* * *}(.001)$ & $-.006^{* * *}(.000)$ & $.029^{* * *}(.001)$ \\
c) ln(income) & $.010^{* * *}(.000)$ & $-.001^{* * *}(.000)$ & $.006^{* * *}(.000)$ \\
\hline Panel II: Linear IV & & & \\
a) baseline & $.022(.056)$ & $-.012(.011)$ & $-.061(.072)$ \\
b) drop 0 income & $.018(.061)$ & $-.013(.012)$ & $-.062(.073)$ \\
c) ln(income) & $.007(.027)$ & $-.006(.006)$ & $-.024(.027)$ \\
\hline \hline Panel III: Linear OLS & & & \\
a) baseline & $.041^{* * *}(.001)$ & $-.005^{* * *}(.000)$ & $.024^{* * *}(.001)$ \\
b) drop 0 income & $.041^{* * *}(.001)$ & $-.005^{* * *}(.000)$ & $.023^{* * *}(.001)$ \\
c) ln(income) & $.010^{* * *}(.000)$ & $-.001^{* * *}(.000)$ & $.006^{* * *}(.000)$ \\
\hline Panel IV: Linear FE & & & \\
a) baseline & $.000(.003)$ & $-.001(.001)$ & $-.001(.004)$ \\
b) drop 0 income & $.000(.004)$ & $-.001(.001)$ & $-.001(.004)$ \\
c) ln(income) & $.001(.001)$ & $-.000(.000)$ & $.001(.001)$ \\
\hline
\end{tabular}

Notes: This table reports OLS, IV and FE estimates of Model 1. Panels I and II uses the IV sample, whereas Panel III and IV uses the FE sample. Panel II uses first born in Rogaland in 1967-1969 dummy variable as the only instrument, A full set of controls is used in all regressions. Standard errors in parentheses are heteroskedastic robust. ${ }^{* * *}$ Significant at $1 \%$ level, ${ }^{* *}$ significant at $5 \%$ level, ${ }^{*}$ significant at $10 \%$ level. 
Table 13: Quadratic OLS, IV and FE - robustness tests III

\begin{tabular}{|c|c|c|c|}
\hline & Education & Dropout & $\begin{array}{c}\text { IQ } \\
\text { (males only) }\end{array}$ \\
\hline \multicolumn{3}{|l|}{ Panel I: Quadratic OLS } & $.032 * * *(.002)$ \\
\hline a)baseline & $-.016^{* * *}(.005)$ & $.008^{* * *}(.001)$ & $-.008 *(.004)$ \\
\hline \multirow[t]{2}{*}{ b) drop 0 income } & $.052^{* * *}(.002)$ & $-.010 * * *(.001)$ & $.033^{* * *}(.003)$ \\
\hline & $-.018^{* * *}(.002)$ & $.008^{* * *}(.001)$ & $-.010 * * *(.005)$ \\
\hline \multicolumn{4}{|l|}{ Panel II: Quadratic IV } \\
\hline \multicolumn{4}{|l|}{ Instruments: Interactions } \\
\hline \multirow[t]{2}{*}{ a) baseline } & $.180^{* *}(.087)$ & $-.030^{*}(.016)$ & $.234^{* *}(.109)$ \\
\hline & $-.302 *(.164)$ & $.042^{*}(.021)$ & $-.401^{* *}(.210)$ \\
\hline \multirow[t]{2}{*}{ b) drop 0 income } & $.174^{* *}(.085)$ & $-.028 *(.015)$ & $.211^{*}(.109)$ \\
\hline & $-.293 *(.160)$ & $.039(.030)$ & $-.363^{*}(.213)$ \\
\hline \multicolumn{4}{|l|}{ Panel III: Quadratic IV } \\
\hline \multicolumn{4}{|l|}{ Instruments: Predicted income } \\
\hline \multirow[t]{2}{*}{ a)baseline } & $.142^{* *}(.072)$ & $-.057 * * *(.013)$ & $.195^{* * *}(.070)$ \\
\hline & $-.228 * *(.107)$ & $.097^{* * *}(.019)$ & $-.323^{* * *}(.106)$ \\
\hline \multirow[t]{2}{*}{ b) drop 0 income } & $.144^{* *}(.068)$ & $-.054^{* * *}(.011)$ & $.168^{* * *}(.063)$ \\
\hline & $-.235^{* *}(.097)$ & $.091^{* * *}(.016)$ & $-.283^{* * *}(.090)$ \\
\hline \multicolumn{4}{|l|}{ Panel IV: Quadratic OLS } \\
\hline \multirow[t]{2}{*}{ a) baseline } & $.069 * * *(.002)$ & $-.012^{* * *}(.000)$ & $.033^{* * *}(.003)$ \\
\hline & $-.050 * * *(.003)$ & $.013^{* * *}(.001)$ & $-.017 * * *(.004)$ \\
\hline \multirow[t]{2}{*}{ b) drop 0 income } & $.069^{* * *}(.002)$ & $-.013^{* * *}(.000)$ & $.033^{* * *}(.003)$ \\
\hline & $-.050 * * *(.003)$ & $.013^{* * *}(.001)$ & $-.017 * * *(.004)$ \\
\hline \multicolumn{4}{|l|}{ Panel V: Quadratic FE } \\
\hline a) baseline & $\begin{array}{r}.041^{* * *}(.008) \\
-.065^{* * *}(.013)\end{array}$ & $\begin{array}{c}-.006^{* * *}(.002) \\
.008^{* * *}(.002)\end{array}$ & $\begin{array}{c}.019^{*}(.010) \\
-.031 *(.014)\end{array}$ \\
\hline \multirow[t]{2}{*}{ b) drop 0 income } & $.042^{* * *}(.008)$ & $-.006^{* * *}(.002)$ & $.013(.012)$ \\
\hline & $-.065^{* * *}(.013)$ & $.008^{* * *}(.002)$ & $-.018(.016)$ \\
\hline
\end{tabular}

Notes: This table reports OLS, IV and FE estimates of Model 2. Panels I and II uses the IV sample, whereas Panel III and IV uses the FE sample. The top row in each specification is the linear coefficient on family income (in $10000 \mathrm{NOK}$ ), and the bottom row is the quadratic coefficient (x 1,000). Panel II uses the set of interacted instruments (born in Rogaland in 1967-1969 dummy variable and interacting the born in Rogaland in 1967-1969 dummy variable with father's college, mother's college, father's age, mother's age and large family) in First Stages I and II, whereas Panel III uses the predicted family income instruments based on the same set of interacted instruments in First Stages I and II. A full set of controls is used in all regressions. Note that the quadratic income is linear income (in 10,000 NOK) multiplied by 100 , hence quadratic income is in 1,000,000 NOK. Standard errors in parentheses are heteroscedastic robust. ${ }^{* * *}$ Significant at $1 \%$ level, ${ }^{* *}$ significant at $5 \%$ level, ${ }^{*}$ significant at $10 \%$ level. 


\section{APPENDIX}

\section{A.1 Proof of Theorem 1}

The proof consists of two steps. The first step proves that $\beta(F E)=\sum_{c=1}^{\bar{c}} w_{c}(F E) \gamma_{s}$, whereas the second steps proves that $\sum_{c=1}^{\bar{c}} w_{c}(F E)=1$.

Step 1: Since $C_{b j}$, and thereby $\Delta C_{j}$, takes on values in the finite set $\{0,1, \ldots, \bar{c}\}$, there are $\sum_{k=1}^{\bar{c}+1} k$ possible combinations of childhood family income between siblings. Under Assumption A3, these combinations generate the following expected differences in siblings' outcomes:

$$
\begin{gathered}
C_{1 j}=0, \Delta C_{j}=0: \quad E\left[\Delta y_{j} \mid C_{1 j}=0, \Delta C_{j}=0\right]=\alpha_{2} \\
C_{1 j}=0, \Delta C_{j}=1: \quad E\left[\Delta y_{j} \mid C_{1 j}=0, \Delta C_{j}=1\right]=\alpha_{2}+\gamma_{1} \\
\vdots \\
C_{1 j}=0, \Delta C_{j}=\bar{c}: \quad E\left[\Delta y_{j} \mid C_{1 j}=0, \Delta C_{j}=\bar{c}\right]=\alpha_{2}+\sum_{c=1}^{\bar{c}} \gamma_{c} \\
C_{1 j}=1, \Delta C_{j}=0: \quad E\left[\Delta y_{j} \mid C_{1 j}=1, \Delta C_{j}=0\right]=\alpha_{2} \\
C_{1 j}=1, \Delta C_{j}=1: \quad E\left[\Delta y_{j} \mid C_{1 j}=1, \Delta C_{j}=1\right]=\alpha_{2}+\gamma_{2} \\
\vdots \\
\begin{array}{c}
C_{1 j}=1, \Delta C_{j}=\bar{c}-1: \quad E\left[\Delta y_{j} \mid C_{1 j}=0, \Delta C_{j}=\bar{c}-1\right]=\alpha_{2}+\sum_{c=2}^{\bar{c}} \gamma_{c} \\
\vdots \\
C_{1 j}=\bar{c}-1, \Delta C_{j}=0: \quad E\left[\Delta y_{j} \mid C_{1 j}=\bar{c}-1, \Delta C_{j}=0\right]=\alpha_{2} \\
C_{1 j}=\bar{c}-1, \Delta C_{j}=1: \quad E\left[\Delta y_{j} \mid C_{1 j}=\bar{c}-1, \Delta C_{j}=1\right]=\alpha_{2}+\gamma_{\bar{c}} \\
C_{1 j}=\bar{c}, \Delta C_{j}=0: \quad E\left[\Delta y_{j} \mid C_{1 j}=\bar{c}, \Delta C_{j}=0\right]=\alpha_{2}
\end{array}
\end{gathered}
$$

From (8), the linear FE estimand can be expressed as

$$
\beta(F E)=\sum_{s=1}^{\bar{c}} \psi_{s} \lambda_{s}
$$

Let $p_{c}(s)$ denote $\operatorname{pr}\left(C_{1 j}=c \mid \Delta C_{j}=s\right)$, and note that $\sum_{c=0}^{\bar{c}} p_{c}(0)=1, \sum_{c=0}^{\bar{c}-1} p_{c}(1)=1$, $\ldots, p_{0}(\bar{c})=1$. By iterating expectations over family income levels $C_{1 j}$ in $\lambda_{s}$, we get:

$$
\lambda_{1}=p_{0}(1) \gamma_{1}+p_{1}(1) \gamma_{2}+\ldots+p_{\bar{c}-1}(1) \gamma_{\bar{c}}=\sum_{c=1}^{\bar{c}} h_{1 c} \gamma_{c}
$$

where $h_{11}=p_{0}(1), h_{12}=p_{1}(1), \ldots, h_{1 \bar{c}}=p_{\bar{c}-1}(1)$.

$$
\begin{aligned}
\lambda_{2}=[ & \left.p_{0}(2)\left(\gamma_{1}+\gamma_{2}\right)+p_{1}(2)\left(\gamma_{2}+\gamma_{3}\right)+\cdots+p_{\bar{c}-2}(2)\left(\gamma_{\bar{c}-1}+\gamma_{\bar{c}}\right)\right] \\
- & {\left[p_{0}(1) \gamma_{1}+p_{1}(1) \gamma_{2}+\cdots+p_{\bar{c}-1}(1) \gamma_{\bar{c}}\right]=\sum_{c=1}^{\bar{c}} h_{2 c} \gamma_{c}, }
\end{aligned}
$$


where $h_{21}=p_{0}(2)-p_{0}(1), h_{22}=p_{0}(2)+p_{1}(2)-p_{1}(1), \ldots, h_{2 \bar{c}}=p_{\bar{c}-2}(2)-p_{\bar{c}-1}(1)$.

$$
\lambda_{\bar{c}}=\sum_{c=1}^{\bar{c}} \gamma_{c}-\left[\left(p_{0}(\bar{c}-1) \sum_{c=1}^{\bar{c}-1} \gamma_{c}\right)+\left(p_{1}(\bar{c}-1) \sum_{c=2}^{\bar{c}} \gamma_{c}\right)\right]=\sum_{c=1}^{\bar{c}} h_{\bar{c}, c} \gamma_{c} .
$$

where $h_{\bar{c}, 1}=1-p_{0}(\bar{c}-1), h_{\bar{c}, 2}=1-p_{0}(\bar{c}-1)-p_{1}(\bar{c}-1), \ldots, h_{\bar{c}, \bar{c}}=1-p_{1}(\bar{c}-1)$.

These expressions show that each $\lambda_{s}$ is a weighted function of the $\gamma_{1}, \ldots, \gamma_{\bar{c}}$ marginal effects. By inserting for $\lambda_{s}$ in $\beta(F E)$, we get

$$
\beta(F E)=\sum_{s=1}^{\bar{c}} \psi_{s} \sum_{c=1}^{\bar{c}} h_{s c} \gamma_{c} .
$$

Reversing the order of summation, we then have

$$
\beta(F E)=\sum_{c=1}^{\bar{c}} w_{c}(F E) \gamma_{c}
$$

where

$$
w_{c}(F E)=\sum_{s=1}^{\bar{c}} \psi_{s} h_{s c}
$$

Step 2: The FE weights $w_{c}(F E)$ sum to 1 since

$$
\begin{gathered}
\sum_{c=1}^{\bar{c}} w_{c}(F E)=\sum_{c=1}^{\bar{c}} \sum_{s=1}^{\bar{c}} \psi_{s} h_{s c} \\
=\sum_{s=1}^{\bar{c}} \psi_{s} \sum_{c=1}^{\bar{c}} h_{s c}
\end{gathered}
$$

and $\sum_{s=1}^{\bar{c}} \psi_{s}=1$ and $\sum_{c=1}^{\bar{c}} h_{s c}=1$ for all $s=1, \ldots, \bar{c}$.

To see that $\sum_{c=1}^{\bar{c}} h_{s c}=1$ for all $s$, note that:

$$
\begin{gathered}
\sum_{c=1}^{\bar{c}} h_{1 c}=\sum_{c=0}^{\bar{c}-1} p_{c}(1)=1 \\
\sum_{c=1}^{\bar{c}} h_{2 c}=2 \sum_{c=0}^{\bar{c}-2} p_{c}(2)-\sum_{c=0}^{\bar{c}-1} p_{c}(1)=1, \\
\vdots \\
\sum_{c=1}^{\bar{c}} h_{\bar{c} c}=\bar{c}-(\bar{c}-1)\left(p_{0}(\bar{c}-1)+p_{1}(\bar{c}-1)\right)=1,
\end{gathered}
$$

QED 


\section{A.2 Proof of Proposition 1}

To prove Proposition 1, a simple example with four values of income is sufficient. Suppose that $C_{b j}$, and thereby $\Delta C_{j}$, takes the values $0,1,2$, or 3 . There are 10 possible combinations of childhood family income between siblings, which under Assumption A3 generate the following expected differences in siblings' outcomes:

$$
\begin{array}{ll}
C_{1 j}=0, \Delta C_{j}=0: & E\left[\Delta y_{j} \mid C_{1 j}=0, \Delta C_{j}=0\right]=\alpha_{2} \\
C_{1 j}=0, \Delta C_{j}=1: & E\left[\Delta y_{j} \mid C_{1 j}=0, \Delta C_{j}=1\right]=\alpha_{2}+\gamma_{1} \\
C_{1 j}=0, \Delta C_{j}=2: & E\left[\Delta y_{j} \mid C_{1 j}=0, \Delta C_{j}=2\right]=\alpha_{2}+\gamma_{1}+\gamma_{2} \\
C_{1 j}=0, \Delta C_{j}=3: & E\left[\Delta y_{j} \mid C_{1 j}=0, \Delta C_{j}=3\right]=\alpha_{2}+\gamma_{1}+\gamma_{2}+\gamma_{3} \\
C_{1 j}=1, \Delta C_{j}=0: & E\left[\Delta y_{j} \mid C_{1 j}=1, \Delta C_{j}=0\right]=\alpha_{2} \\
C_{1 j}=1, \Delta C_{j}=1: & E\left[\Delta y_{j} \mid C_{1 j}=1, \Delta C_{j}=1\right]=\alpha_{2}+\gamma_{2} \\
C_{1 j}=1, \Delta C_{j}=2: & E\left[\Delta y_{j} \mid C_{1 j}=1, \Delta C_{j}=2\right]=\alpha_{2}+\gamma_{2}+\gamma_{3} \\
C_{1 j}=2, \Delta C_{j}=0: & E\left[\Delta y_{j} \mid C_{1 j}=2, \Delta C_{j}=0\right]=\alpha_{2} \\
C_{1 j}=2, \Delta C_{j}=1: & E\left[\Delta y_{j} \mid C_{1 j}=2, \Delta C_{j}=1\right]=\alpha_{2}+\gamma_{3} \\
C_{1 j}=3, \Delta C_{j}=0: & E\left[\Delta y_{j} \mid C_{1 j}=3, \Delta C_{j}=0\right]=\alpha_{2}
\end{array}
$$

From (8), the linear FE estimand can be expressed as

$$
\beta(F E)=\sum_{s=1}^{3} \psi_{s} \lambda_{s}
$$

Let $p_{c}(s)$ denote $\operatorname{pr}\left(C_{1 j}=c \mid \Delta C_{j}=s\right)$, and note that $p_{0}(1)+p_{1}(1)+p_{2}(1)=1$ and $p_{0}(2)+p_{1}(2)=1$. By iterating expectations over family income levels $C_{1 j}$ in $\lambda_{s}$, we get

$$
\begin{gathered}
\lambda_{3}=\left[\gamma_{1}+\gamma_{2}+\gamma_{3}\right]-\left[p_{0}(2)\left(\gamma_{1}+\gamma_{2}\right)+p_{1}(2)\left(\gamma_{2}+\gamma_{3}\right)\right]=\left(1-p_{0}(2)\right) \gamma_{1}+\left(1-p_{1}(2)\right) \gamma_{3} \\
\left.\lambda_{2}=\left[p_{0}(2)\left(\gamma_{1}+\gamma_{2}\right)+p_{1}(2)\left(\gamma_{2}+\gamma_{3}\right)\right]-\left[p_{0}(1) \gamma_{1}+p_{1}(1) \gamma_{2}+p_{2}(1)\right) \gamma_{3}\right] \\
=\left(p_{0}(2)-p_{0}(1)\right) \gamma_{1}+\left(1-p_{1}(1)\right) \gamma_{2}+\left(p_{1}(2)-p_{2}(1)\right) \gamma_{3}
\end{gathered}
$$

and

$$
\lambda_{1}=p_{0}(1) \gamma_{1}+p_{1}(1) \gamma_{2}+p_{2}(1) \gamma_{3},
$$

Using these expressions for $\lambda_{1}, \lambda_{2}$, and $\lambda_{3}$, we get

$$
\beta(F E)=\sum_{c=1}^{3} w_{c}(F E) \gamma_{c}
$$

where

$$
\begin{gathered}
w_{1}(F E)=\psi_{3}+p_{0}(2)\left(\psi_{2}-\psi_{3}\right)+p_{0}(1)\left(\psi_{1}-\psi_{2}\right), \\
w_{2}(F E)=\psi_{2}+p_{1}(1)\left(\psi_{1}-\psi_{2}\right),
\end{gathered}
$$

and 


$$
w_{3}(F E)=\psi_{3}+p_{1}(2)\left(\psi_{2}-\psi_{3}\right)+p_{2}(1)\left(\psi_{1}-\psi_{2}\right) .
$$

Since $w_{1}(F E)+w_{2}(F E)+w_{3}(F E)=1$, we know that at least some of these FE weights must be positive. However, there is nothing that ensures that all $w_{c}(F E)$ are non-negative, even though $\psi_{c}$ and $p_{c}(s)$ are non-negative for all $c$ and $s$. Specifically, if $\psi_{2}$ is sufficiently large compared to $\psi_{3}$, then $w_{3}(F E)$ or $w_{1}(F E)$ can be negative, depending on the values of the conditional probabilities $p_{c}(s)$.

For example, consider the case where $p_{0}(2)=0$ (implying that $\left.p_{1}(2)=1\right)$ and $p_{0}(1)=$ 1 (implying that $p_{1}(1)=0$ and $p_{2}(1)=0$ ). In this case, $w_{1}(F E)=\psi_{1}+\psi_{3}-\psi_{2}$, $w_{2}(F E)=\psi_{2}$, and $w_{3}(F E)=\psi_{2}$. If the population share experiencing $\Delta C_{j}=2$ is sufficiently large, then $w_{1}(F E)$ will be negative. To see this, suppose that the withinfamily income variation is such that $\operatorname{pr}\left(\Delta C_{j}=0\right)=.05$, and $\operatorname{pr}\left(\Delta C_{j}=1\right)=.4$. Then, $w_{1}(F E)$ will be negative whenever $\operatorname{pr}\left(\Delta C_{j}=3\right)<.23$ (implying that $\operatorname{pr}\left(\Delta C_{j}=2\right)>.32$ ).

Along the same lines, it is straightforward to show that some (but not all) $w_{c}(F E)$ also can be negative when $\bar{c}>3$.

QED

\section{A.3 Computation of FE Decomposition}

In order to compute the linear FE weights defined in Theorem 1, we use an iterative algorithm. Note that we can re-write FE decomposition as:

$$
\begin{gathered}
\beta(F E)=\tilde{\psi}_{1} E\left[\Delta y_{j} \mid \Delta C_{j}=0\right]+\tilde{\psi}_{2} E\left[\Delta y_{j} \mid \Delta C_{j}=1\right] \\
+\cdots+\tilde{\psi}_{\bar{c}-1} E\left[\Delta y_{j} \mid \Delta C_{j}=\bar{c}-1\right]+\tilde{\psi}_{\bar{c}} E\left[\Delta y_{j} \mid \Delta C_{j}=\bar{c}\right]
\end{gathered}
$$

where $\tilde{\psi}_{1}=-\psi_{1}, \tilde{\psi}_{s}=\psi_{s-1}-\psi_{s}$ for $s=1,2, \ldots, \bar{c}-1$, and $\tilde{\psi}_{\bar{c}}=\psi_{\bar{c}}$.

Our iterative algorithm is as follows:

Step 1: Set $w_{c}(F E)=0$ for all $c=0,1, \ldots, \bar{c}$.

Step 2: Loop over all possible income changes $0,1, \ldots, \bar{c}$.

Step 3: For each income change $s$, loop over all first sibling income levels indexed $c=$ $0,1, \ldots, \bar{c}$. We re-set $w_{c}(F E)$ as

$$
w_{c}(F E)=w_{c}(F E)+\tilde{\psi}_{c} p_{c}(s) .
$$

Note that for infeasible combinations of changes in income $s$ and levels of first sibling income $c, p_{c}(s)=0$. Replacing $\psi_{s}$ and $p_{c}(s)$ with their sample analog estimators, allows us to estimate $w_{c}(F E)$ for all $c$. 